\title{
Simplified Expressions for Elastic Lateral Torsional Buckling of Wooden Beams
}

\author{
by
}

\author{
Arash Sahraei ${ }^{\text {a, }}$, Payam Pezeshky ${ }^{a}$, Magdi Mohareb ${ }^{a}$, and Ghasan Doudak ${ }^{\text {a }}$ \\ ${ }^{a}$ Department of Civil Engineering, University of Ottawa, Ottawa, ON, Canada K1N 6N5
}

\begin{abstract}
A beam finite element formulation is developed for the elastic lateral torsional buckling analysis of wood beams with rectangular cross-sections. The formulation accounts for moment gradient, load height, and pre-buckling deformation effects. The validity of the finite element and underlying variational principle is established through comparisons with critical moments obtained by 3D FEA simulations and experimental results. The validated variational expression is then adopted to develop approximate analytical expressions that separately characterize the effects of moment gradient, partial twist restraints that may exist at beam-ends, load height, and pre-buckling deformation effects. Dimensionless coefficients were formulated to characterize each effect for simple beams and cantilevers under common loading scenarios. The derived coefficients are then consolidated into a unified framework that accounts for all effects combined to predict the elastic lateral torsional buckling capacity of wooden beams.
\end{abstract}

Keywords: Lateral torsional buckling, wood beams, finite element, simplified solution, moment gradient effect, load height effect, pre-buckling deformation.

This article is to be cited as:

Sahraei A, Pezeshky P, Mohareb M, Doudak G (2018), Simplified expressions for elastic lateral torsional buckling of wooden beams, Engineering Structures, 174: 229-241.

A copy-edited version of this article can be obtained at: $\underline{\text { https://doi.org/10.1016/j.engstruct.2018.07.042 }}$

\footnotetext{
*Corresponding Author: Email: asahr012@uottawa.ca
} 


\section{Nomenclature}

\begin{tabular}{|c|c|}
\hline$b$ & Width of cross-section \\
\hline$C_{b}$ & Moment gradient coefficient \\
\hline$C_{L}$ & Load height coefficient \\
\hline$C_{p}$ & Pre-buckling deformation coefficient \\
\hline$C_{r}$ & Partial twist coefficient \\
\hline$d$ & Cross-section depth \\
\hline$E$ & Modulus of elasticity \\
\hline EL & Effective Length \\
\hline$G$ & Shear modulus \\
\hline$h$ & Cross-section height \\
\hline $\mathbf{H}_{1}$ & Vectors of the Hermitian polynomials \\
\hline $\mathbf{H}_{2}$ & Vector of Linear interpolation functions \\
\hline$I_{z z}, I_{y y}$ & $\begin{array}{l}\text { Moments of inertia of the cross-section about z-axis and y- } \\
\text { axis, respectively }\end{array}$ \\
\hline$J$ & Saint Venant torsional constant \\
\hline$k$ & Load height parameter \\
\hline$\left[K_{E}\right]$ & Elastic stiffness matrix \\
\hline$\left[K_{G}\right]$ & Geometric stiffness matrix \\
\hline$L$ & Member span \\
\hline$L_{e}$ & Effective length \\
\hline$M_{a}, M_{b}, M_{c}$ & Moments at quarter points \\
\hline$M_{c r}$ & Critical moment \\
\hline$M_{0}$ & Maximum bending moment \\
\hline$M(x)$ & $\begin{array}{l}\text { Strong-axis bending moment as obtained from pre-buckling } \\
\text { analysis }\end{array}$ \\
\hline$M_{u}$ & Reference elastic critical moment for the hypothetical case \\
\hline & $\begin{array}{l}\text { of a beam with simply supported ends relative to lateral } \\
\text { displacements and twist }\end{array}$ \\
\hline MGF & Moment Gradient Factor \\
\hline$P$ & Externally applied transverse point load \\
\hline$q_{y}$ & Distributed transverse load \\
\hline$R$ & Partial twist stiffness at beam end \\
\hline$u$ & Lateral displacement \\
\hline$\left\langle u_{n}\right\rangle^{T}$ & Vector of lateral nodal displacements \\
\hline
\end{tabular}




$\begin{array}{ll}\left\{u_{s}\right\} & \text { Vector of unknown displacements of the structure } \\ U & \text { Internal strain energy } \\ V & \text { Load potential energy gained } \\ v & \text { Transverse displacement } \\ y_{q} & \text { Height of the distributed load above section centroid } \\ y_{p} & \text { Height of a point load above section centroid } \\ \alpha & \text { Twisting stiffness ratio as defined in Eq. (13)b } \\ \lambda & \text { Load multiplier } \\ \pi & \text { Total potential energy } \\ \theta_{x} & \text { Angle of twist } \\ \left\langle\theta_{x}\right\rangle^{T} & \text { Vector of nodal angles of twist }\end{array}$

\section{Motivation}

Elastic lateral torsional buckling (LTB) is a key failure mode that typically governs the capacity of long-span laterally unsupported wooden beams. The elastic LTB strength is known to depend on wood constitutive properties, beam geometry, load distributions, end partial fixity restraints, load height relative to section centroid, and pre-buckling deformation. The development of LTB provisions in present design standards (e.g., CAN-CSA O86-14 [1], AFPA-TR14 [2], ANSI/AWC-NDS-2015 [3]) have been primarily motivated by attaining simplified design equations. To reduce the number of parameters influencing the design, standards have adopted a number of simplifying assumptions regarding constitutive properties of wood. The resulting design equations for LTB, while simple, are restricted to a rather limited number of problems. Further, under present standard methodologies, it is unclear to the designer how to modify present design provisions to tackle deviations from material properties, boundary conditions, loading, end conditions, etc. from those postulated in formulating present design rules. Within this context, the present study aims at developing a more transparent and flexible, yet relatively simple, framework to quantify the LTB strength of laterally unsupported beams. The proposed solution incorporates key factors that affect the LTB strength of beams through independent coefficients based on approximate energy solutions. 


\section{Literature review}

This section reviews past research on LTB of timber beams, followed by a comparative summary of LTB provisions in design standards for wooden members, and then presents an overview of theoretical lateral torsional buckling studies.

Past experimental research on the LTB of wood beams includes the work of Hooley and Madsen [4] who conducted a LTB experimental program on wooden beams with rectangular cross-sections and used them to develop design equations for elastic and inelastic LTB strength. Hindman et al. [5] experimentally investigated the LTB of unbraced cantilevers and compared test results with design standard provisions. In a subsequent study, Hindman et al. [6] expanded their work to investigate the LTB of Ijoists beams. Balaz [7] investigated the LTB of timber beams with mono-symmetric cross-sections and proposed an expression to calculate the elastic critical moments. Burow et al. [8] and Burow et al. [9] provided an assessment of LTB design equations in standards by testing simply-supported and cantilevered I-joists within a wide range of slenderness ratios. Xiao et al. [10] conducted a full-scale experimental investigation on the elastic LTB of simply supported beams with rectangular cross-sections. A 3D finite element model was also developed to study the sensitivity of material properties and the effects of load height and boundary support height on the LTB capacity. Xiao et al. [11] also investigated the effect of orthotropic properties on the LTB capacity of wooden beams. Balaz and Kolekova [12] provided a generalized critical moment framework for critical moment expressions of beams with mono-symmetric cross-sections. Du et al. developed non-sway [13] and sway [14] models for LTB analysis of wooden beams. The authors also provided a comparison between results for both models [15]. Hu et al. [16] developed energy-based solutions for the LTB analysis of wooden beams with a flexible mid-span lateral brace subjected to uniformly distributed loads or mid-span point load. The same researchers also developed [17] analytical solutions and conducted a parametric study to investigate the combined effect of bracing height and load height on the elastic LTB capacity of wooden beams.

Stability behaviour of wood beam-columns have been investigated by various researchers. Among them is the study of Buchanan [18] who developed a model to predict both instability and material strength failures of lumbers under combined bending 
and axial loading. Zahn [19] proposed a design criterion for wood members under combined axial and bending loads. Zahn [20] conducted an elastic buckling analysis in beam-columns to develop a general interaction equation for use in timber design. Koka [21] developed finite element solution to predict instability and material strength failures of lumber elements under combined bending and axial loading. Bell and Eggen [22] investigated the stability of beams, columns and beam-columns under combined bending and compression action using both linearized buckling and geometric nonlinear analyses. Steiger and Fontana [23] presented the results of bending-axial interaction tests performed experimentally on 220 solid rectangular specimens. Song and Lam [24], Song and Lam [25], and Song and Lam [26] performed three dimensional stability analysis for braced wood beam-columns under biaxial eccentric loading and determined lateral bracing requirements of wood beam-columns. Also, Zahn [27], Zahn [28] and Zahn [29] formulated analytically the governing equilibrium conditions for wooden rectangular beams laterally restrained along the beam centroidal axis by the shear action of deck boards.

The design guidelines for lateral torsional buckling of timber beams have been considered in standards such as CAN-CSA O86-14 [1], AFPA-TR14 [2], ANSI/AWCNDS-2015 [3], and EN 1995-1-1: 2004 [30] where the critical moment is influenced by various parameters (e.g., moment distribution, load height, torsional flexibility at end connections, etc.). Table 1 shows the various features captured in the different standards.

Past studies on the LTB analysis for flexural members primarily focused on developing finite element formulations for wide flange steel sections. A non-exhaustive review includes the work of Krajcinovic [31] and Barsoum and Gallagher [32] who developed finite elements that capture warping effects. Shear deformation effects were included in the studies of Powel and Klingner [33], Erkmen and Mohareb [34], Attard and Kim [35], Wu and Mohareb [36], Erkmen [37], and Sahraei and Mohareb [38]. Pre-buckling deformation effects were investigated in the work Roberts and Azizian [39], Pi and Trahair [40], Andrade and Camotim [41], Machado and Cortínez [42], Erkmen and Attard [43], and Mohri et al. [44]. In a recent study, Pezeshky [45] developed a generalized lateral torsional buckling formulation that captures warping, shear deformation, pre-buckling deformation and distortion. The present solution is based on a 
modification of the functional derived in Pi and Trahair [46] specifically tailored to retain features relevant to rectangular wood sections (i.e., pre-buckling deformation effects), while discarding non-important effects (e.g., warping, shear deformation, and distortion) and incorporating partial twist end-restraint effects.

Table 1 Methods used to incorporate various features in the stability design of timber beams with pin rectangular sections

\begin{tabular}{|c|c|c|c|c|}
\hline Standards & $\begin{array}{c}\text { Moment } \\
\text { Distribution }\end{array}$ & Load Height & $\begin{array}{c}\text { Torsional } \\
\text { flexibility } \\
\text { at end } \\
\text { connections }\end{array}$ & $\begin{array}{l}\text { Pre-buckling } \\
\text { Deformation }\end{array}$ \\
\hline $\begin{array}{c}\text { CAN- } \\
\text { CSA O86-14 } \\
{[1]}\end{array}$ & $\mathrm{EL}^{*}$ & $x$ & $\begin{array}{c}\text { Increase } \\
\text { unsupported } \\
\text { length by } \\
1.15^{* *} \\
\end{array}$ & Not captured \\
\hline \multirow{2}{*}{$\begin{array}{c}\text { AFPA-TR14 } \\
\text { [2] }\end{array}$} & $\mathrm{MGF}^{* * *}$ & $C_{e}=\sqrt{1+\eta^{2}}-\eta$ & \multirow{2}{*}{$\begin{array}{c}\text { Increase } \\
\text { unsupported } \\
\text { length by } \\
1.15\end{array}$} & \multirow{2}{*}{ 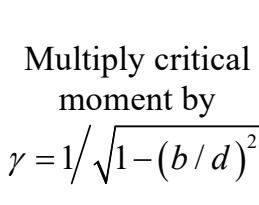 } \\
\hline & EL & \multirow{3}{*}{$\begin{array}{l}\text { For top face loading: } \\
\text { Increase } \mathrm{L}_{\mathrm{e}} \text { by } 3 \mathrm{~d} \\
\text { For bottom face loading: } \\
\text { Decrease } \mathrm{L}_{\mathrm{e}} \text { by d }\end{array}$} & & \\
\hline $\begin{array}{l}\text { ANSI/AWC- } \\
\text { NDS-2015 [3] }\end{array}$ & EL & & $\begin{array}{c}\text { Increase } \\
\text { unsupported } \\
\text { length by } \\
1.15 \\
\end{array}$ & $\begin{array}{c}\begin{array}{c}\text { Multiply critical } \\
\text { moment by }\end{array} \\
\gamma=1 / \sqrt{1-(b / d)^{2}}\end{array}$ \\
\hline $\begin{array}{c}\text { EN 1995-1-1: } \\
2004[30]\end{array}$ & EL & & $\begin{array}{c}\text { Not } \\
\text { captured }\end{array}$ & Not captured \\
\hline
\end{tabular}

${ }^{*} \mathrm{EL}=$ Effective Length

${ }^{* *}$ CAN-CSA O86-14 adopts the factor 1.15 as proposed by Hooley and Madsen [4]

${ }^{* * *} \mathrm{MGF}=$ Moment Gradient Factor

$b=$ width of section, $d=$ depth of section, $\eta=\left(k d / 2 L_{u}\right) \sqrt{E I_{y y} / G J}$

\section{Statement of the problem}

Given is a laterally unsupported prismatic wooden beam with a rectangular section subjected to general transverse loads $q(x)$ acting at a distance $y_{q}$ above the centroidal axis. Under the transverse loads, the beam centroid undergoes a transverse displacement $v(x)$ from the un-deformed state (Configuration 1) to deformed Configuration 2 as shown in Fig. 1. The transverse loads are then assumed to increase to $\lambda q(x)$, where $\lambda$ is a load multiplier. Under load increase, the beam is assumed to undergo a transverse displacement $\lambda v(x)$ to attain the state of onset of buckling (Configuration 3 ). At the 
onset of buckling, the beam has tendency to undergo lateral torsional buckling characterized by lateral displacement $u(x)$ and angle of twist $\theta_{x}(x)$. It is required to determine the load level $\lambda q(x)$ (or critical moment $\lambda M$ ) at the onset of buckling.

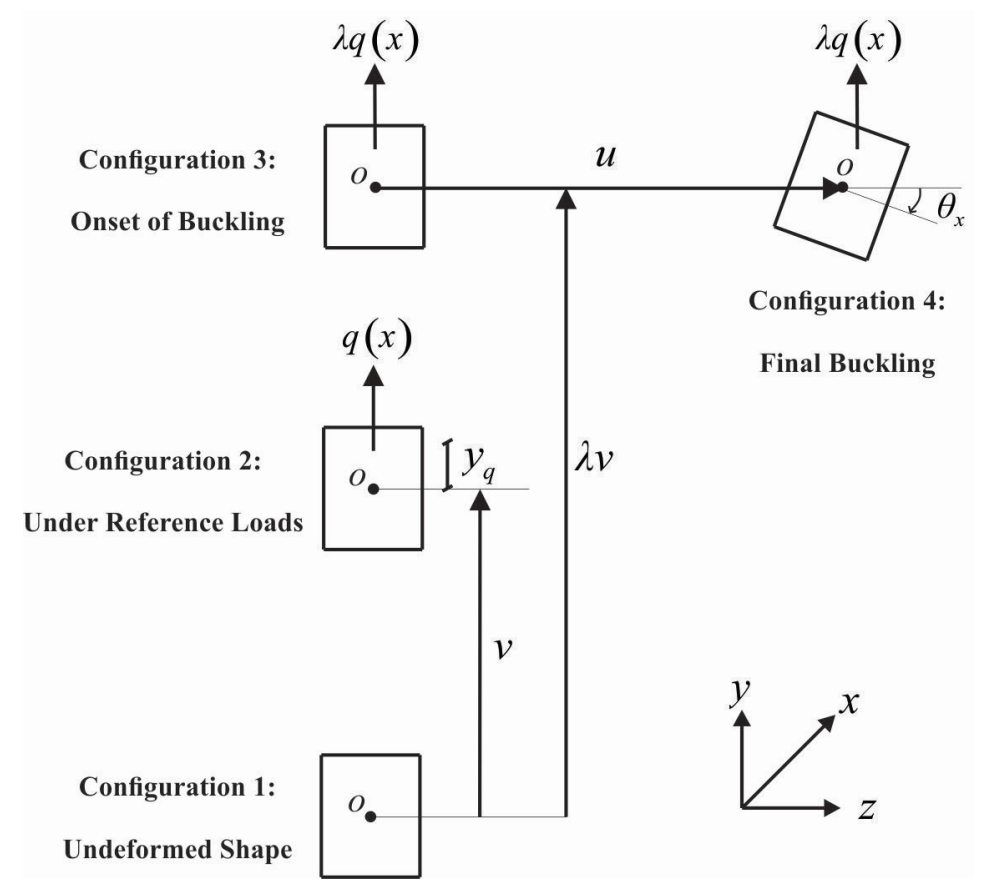

Fig. 1 Various stages of deformation

\section{Assumptions}

The assumptions of the solutions are:

1. The beam is prismatic with a rectangular cross-section. For rectangular sections, past studies $([16,47,48])$ have shown that the contribution of warping is negligible on the predicted lateral torsional buckling resistance. Also, the omission of warping leads to considerable simplifications in the approximate solutions sought.

2. Wood is modelled as a homogeneous elastic orthotropic material. Given that wood properties in the tangential and radial directions are nearly identical, the nine orthotropic constants characterizing the constitutive behaviour reduce to six independent parameters. Based on 3D finite element buckling analyses, Xiao et al. [11] have shown that only two of the six constitutive properties have impact on the elastic lateral buckling capacity; (1) the longitudinal Young modulus E, and (2) the 
shear modulus $G$ for shear stresses acting on the normal plane either in the radial or tangential directions. The present formulation thus characterizes the constitutive behaviour of wood only by two independent constants $E$ and $G$ in a manner akin to isotropic materials.

3. The effect of pre-buckling deformations is incorporated in the solution. While most past studies have primarily focussed on I-shaped sections, and have thus omitted the effect of pre-buckling deformations, such effects have been reported to gain significance for beams with relatively shallow rectangular cross-sections $([2,3])$.

4. As transverse loads are frequently offset from the beam centroidal axis in practical situations, the solution captures the load height effect.

5. Past studies (e.g., Hooley and Madsen [4]) and design standards ([1, 2]) suggest that typical end connection details provide only partial torsional end restraints. Thus, the solution sought incorporates the effect of end partial twist restraint.

6. Given that the width to depth ratio of typical wood cross-sections is relatively large, cross-sectional distortional effects are omitted. The adoption of similar assumptions have led to solutions in excellent agreement with 3D FEA which incorporate distortional effects $([47,48])$.

\section{Variational principle}

Under the above assumptions, after omitting distortional, warping, and shear deformation [45] while retaining pre-buckling deformation effects, one obtains the following expression for total potential energy functional $\pi$

$\pi \approx U_{1}+U_{2}+V_{1}+V_{2}+V_{3}+V_{4}$

where

$$
\begin{aligned}
& U_{1}=\frac{1}{2} \int_{0}^{L} E I_{y y} u^{\prime \prime}(x)^{2} d x \\
& U_{2}=\frac{1}{2} \int_{0}^{L} G J \theta_{x}^{\prime}(x)^{2} d x \\
& V_{1}=\frac{1}{2} \int_{0}^{L} \lambda q_{y}(x) y_{q}(x) \theta_{x}(x)^{2} d x
\end{aligned}
$$




$$
\begin{aligned}
& V_{2}=\int_{0}^{L} \lambda M(x) u^{\prime \prime}(x) \theta_{x}(x) d x \\
& V_{3}=-\int_{0}^{L} \lambda \frac{I_{y y}}{I_{z z}} M(x) u^{\prime \prime}(x) \theta_{x}(x) d x \\
& V_{4}=-\frac{1}{2} \int_{0}^{L} \lambda^{2} \frac{[M(x)]^{2}}{E I_{z z}}\left(1-\frac{I_{y y}}{I_{z z}}\right) \theta_{x}(x)^{2} d x
\end{aligned}
$$

and $E$ is the modulus of elasticity, $I_{y y}$ is the moment of inertia about y-axis, $I_{z z}$ is the moment of inertia about z-axis, $G$ is shear modulus, $J$ is Saint-Venant torsional constant. For a rectangular section, $J$ is computed by the expression $J \approx\left(b^{3} d / 3\right)\left[1-0.63(b / d)+0.052(b / d)^{5}\right]$ (AFPA-TR14 [2]), $q_{y}(x)$ is the distributed load along the beam, $y_{q}$ is the height of the load $q_{y}(x)$ from the section centroid, $M(x)$ is the bending moment distribution. Functions $u$ and $\theta_{x}$ denote the lateral displacement and angle of twist respectively, and all integrals are performed over span $L$ of the beam. The terms $U_{1}$ and $U_{2}$ are the internal strain energies stored due to weak axis bending and Saint-Venant torsion, respectively. $V_{1}$ is the destabilizing effect due to load height effect while $V_{2}$ is the conventional destabilizing term due to strong axis bending moments. The terms $U_{1}, U_{2}, V_{1}$, and $V_{2}$ appear in conventional finite element formulation [32] while the terms $V_{3}$ and $V_{4}$ appear only when pre-buckling terms are retained in the formulation. Only when $1-I_{y y} / I_{z z} \approx 1$, can the terms $V_{3}$ and $V_{4}$ be neglected relative to $V_{2}$. This happens to be the case for most flanged sections and hence most previous solutions do not retain these terms. However, for beams with relatively shallow rectangular crosssections, such an approximation can underestimate the critical moments. Hence, $V_{3}$ and $V_{4}$ are retained in the present formulation.

As will be discussed under Section 8, the variational principle defined in Eqs. (1) and (2) a-f will serve as a basis for developing a series of approximate coefficients intended for design. In order to assess the accuracy of such approximate solutions, an FEA is 
developed based on the variational expression in Eq. (1). The specifics of the formulation are described in the following section.

\section{Finite element formulation}

The lateral displacement $u(x)$ and angle of twist $\theta_{x}(x)$ are related to the nodal displacements and rotations $\mathbf{u}_{\mathbf{n}}^{\mathbf{T}}=\left\langle\begin{array}{llll}u_{1} & u_{1}^{\prime} & u_{2} & u_{2}^{\prime}\end{array}\right\rangle$ and $\boldsymbol{\theta}_{\mathbf{n}}^{\mathbf{T}}=\left\langle\begin{array}{ll}\theta_{x 1} & \theta_{x 2}\end{array}\right\rangle$ through

$u=\mathbf{H}_{1}^{\mathrm{T}} \mathbf{u}_{\mathrm{n}}, \quad \theta_{x}=\mathbf{H}_{2}^{\mathrm{T}} \boldsymbol{\theta}_{\mathbf{n}}$

where

$$
\mathbf{H}_{1}^{\mathbf{T}}=\left\langle 1-3\left(\frac{x}{L}\right)^{2}+2\left(\frac{x}{L}\right)^{3}-x+\frac{2 x^{2}}{L}-\frac{x^{3}}{L^{2}} \quad 3\left(\frac{x}{L}\right)^{2}-2\left(\frac{x}{L}\right)^{3}-\frac{x^{3}}{L^{2}}+\frac{x^{2}}{L}\right\rangle
$$

is the vector of the Hermitian polynomials, and

$$
\mathbf{H}_{2}^{\mathbf{T}}=\left\langle 1-\frac{x}{L} \quad \frac{x}{L}\right\rangle
$$

is the vector of linear interpolation functions. From Eqs. (3)a-b by substituting into Eq. (1), and evoking the stationary conditions, one obtains the eigenvalue problem:

$$
\left[\mathbf{K}_{\mathbf{E}}-\lambda \mathbf{K}_{\mathbf{G}}\right] \mathbf{u}_{\mathbf{s}}=\mathbf{0}
$$

where $\mathbf{K}_{\mathbf{E}}$ is the elastic stiffness matrix, $\mathbf{K}_{\mathbf{G}}$ is the geometric stiffness matrix, and $\mathbf{u}_{\mathbf{s}}{ }^{\mathbf{T}}=\left\langle\begin{array}{ll}\mathbf{u}_{\mathbf{n}} & \boldsymbol{\theta}_{\mathbf{n}}\end{array}\right\rangle$ is the nodal displacement vector. The above finite element solution captures the effects of load height and pre-buckling deformations and will thus serve as a benchmark to assess the approximate solutions to be developed in Section 8 .

\section{Verification}

In a recent study, Xiao et al. [10] tested 18 specimens consisting of Spruce-Pine-Fir (SPF) No. 1/No. 2 grade lumber joists. Specimen geometries (Columns 2-4 of Table 2) were selected such that elastic lateral torsional buckling failure governs the capacity of the joists and the mechanical properties for each specimens were determined using nondestructive testing (Columns 5-7 of Table 2). All beams were simply supported at both ends and subject to a mid-span point load acting at the top face of the beam. Results based on the experimental test were compared with those based on ABAQUS 3D finite 
element solution, where C3D8 brick element from the ABAQUS library was used to mesh the beams. The C3D8 element has eight nodes and three translational degrees of freedom (DOFs) per node. The experimental and numerical results in Xiao et al. [10] are thus used as benchmarks to assess the validity of the variational principle in Section 5 through comparisons with the predictions of resulting finite element formulation presented in Section 6. Excellent agreement is attained between results based on 3D FEA (Column 9) and the present FEA solution (column 10), where the ratio of the two solutions (Column 12) varied from 1.01 to 1.03 with an average of 1.01. Reasonable agreement is attained between the present finite element predictions and the experimental results where ratios varied from 0.83 to 1.31 with an average value of 1.04 and a standard deviation of 0.14 in a manner similar to the 3D FEA results. As reported in Xiao et al. [10], the difference between experimental results and FEA predictions is attributed to the spatial variability within the material and the geometric imperfections in the specimens; both effects not captured within the FEA model.

Table 2 Comparison of critical moments between test, 3D FEA, and FEA (present study) results

\begin{tabular}{|c|c|c|c|c|c|c|c|c|c|c|c|}
\hline \multirow{2}{*}{$\begin{array}{l}\text { Spec } \\
\text { No. } \\
(1)\end{array}$} & \multicolumn{3}{|c|}{$\begin{array}{c}\text { Geometric Properties } \\
(\mathrm{mm})\end{array}$} & \multicolumn{3}{|c|}{$\begin{array}{c}\text { Material Properties } \\
(\mathrm{MPa})\end{array}$} & \multicolumn{3}{|c|}{ Critical Moment (kNm) } & \multicolumn{2}{|c|}{ Ratio } \\
\hline & $\begin{array}{l}\text { Width } \\
\text { (2) }\end{array}$ & $\begin{array}{l}\text { Depth } \\
\text { (3) }\end{array}$ & $\begin{array}{c}\text { Span } \\
(4)\end{array}$ & $\begin{array}{c}E \\
(5)\end{array}$ & $\begin{array}{l}\text { G } \\
(6)\end{array}$ & $\begin{array}{l}\mathrm{E} / \mathrm{G} \\
(7)\end{array}$ & $\begin{array}{l}\text { Test } \\
(8)\end{array}$ & $\begin{array}{c}3 \mathrm{D} \\
\text { FEA } \\
(9)\end{array}$ & $\begin{array}{c}\text { Present } \\
\text { FEA } \\
(10)\end{array}$ & $\begin{array}{l}(10) /(8) \\
=(11)\end{array}$ & $\begin{array}{l}(10) /(9) \\
=(12)\end{array}$ \\
\hline 1 & 38 & 182 & 4200 & 10434 & 501 & 21 & 3.34 & 3.21 & 3.25 & 0.97 & 1.01 \\
\hline 2 & 38 & 181 & 4200 & 9022 & 614 & 15 & 3.72 & 3.33 & 3.38 & 0.91 & 1.02 \\
\hline 3 & 38 & 180 & 4200 & 11185 & 558 & 20 & 3.58 & 3.47 & 3.52 & 0.98 & 1.01 \\
\hline 4 & 38 & 181 & 4200 & 10111 & 548 & 18 & 3.62 & 3.31 & 3.34 & 0.92 & 1.01 \\
\hline 5 & 39 & 180 & 4200 & 9947 & 540 & 18 & 3.62 & 3.49 & 3.53 & 0.98 & 1.01 \\
\hline 6 & 38 & 234 & 3600 & 11217 & 542 & 21 & 4.60 & 5.05 & 5.08 & 1.10 & 1.01 \\
\hline 7 & 38 & 232 & 3600 & 9745 & 535 & 18 & 5.67 & 4.68 & 4.71 & 0.83 & 1.01 \\
\hline 8 & 38 & 235 & 3600 & 5563 & 569 & 10 & 3.44 & 3.80 & 3.86 & 1.12 & 1.02 \\
\hline 9 & 38 & 231 & 3600 & 12339 & 606 & 20 & 6.30 & 5.52 & 5.57 & 0.88 & 1.01 \\
\hline 10 & 38 & 235 & 3600 & 7619 & 550 & 14 & 4.87 & 4.30 & 4.35 & 0.89 & 1.01 \\
\hline 11 & 39 & 234 & 3600 & 8092 & 632 & 13 & 4.78 & 5.13 & 5.20 & 1.09 & 1.01 \\
\hline 12 & 38 & 234 & 3600 & 9009 & 515 & 17 & 4.51 & 4.46 & 4.49 & 1.00 & 1.01 \\
\hline 13 & 38 & 284 & 4200 & 6668 & 451 & 15 & 3.16 & 3.77 & 3.83 & 1.21 & 1.02 \\
\hline 14 & 38 & 285 & 4200 & 7171 & 521 & 14 & 3.28 & 4.24 & 4.30 & 1.31 & 1.01 \\
\hline 15 & 39 & 286 & 4200 & 6469 & 479 & 14 & 3.68 & 4.18 & 4.25 & 1.15 & 1.02 \\
\hline 16 & 38 & 285 & 4200 & 5960 & 515 & 12 & 3.87 & 3.85 & 3.94 & 1.02 & 1.02 \\
\hline 17 & 38 & 281 & 4200 & 7880 & 442 & 18 & 3.19 & 3.99 & 4.03 & 1.26 & 1.01 \\
\hline 18 & 38 & 284 & 4200 & 5491 & 720 & 8 & 4.53 & 4.42 & 4.56 & 1.01 & 1.03 \\
\hline & & & & & & & \multicolumn{3}{|c|}{ Minimum= } & 0.83 & 1.01 \\
\hline & & & & & & & \multicolumn{3}{|c|}{ Maximum= } & 1.31 & 1.03 \\
\hline & & & & & & & \multicolumn{3}{|c|}{ Average $=$} & 1.04 & 1.01 \\
\hline & & & & & & & \multicolumn{3}{|c|}{ Standard Deviation $=$} & 0.14 & 0.01 \\
\hline
\end{tabular}




\section{Proposed framework for elastic critical moment expression}

The present study seeks an expression that approximately characterizes the elastic critical moment $M_{c r}$ for a wood beam of rectangular sections. The approach proposes an expression of the form

$$
M_{c r} \approx C_{r} C_{b} C_{L} C_{p} M_{u}
$$

where

$$
M_{u}=\frac{\pi}{L} \sqrt{E I_{y y} G J}
$$

is the reference elastic critical moment for the hypothetical case of a beam of span $L$ with lateral displacements and twist restraints at both ends subjected to uniform moments. The reference moment $M_{u}$ does not account for effects such as partial twist restraint, moment gradient, load height, nor pre-buckling deformation. Such effects will be accounted for separately through the modifiers $C_{r} C_{b} C_{L} C_{p}$. Specifically, $C_{r}$ is a coefficient that accounts for partial twist restraint at beam-ends, $C_{b}$ is a coefficient that accounts for the non-uniform moment distribution within the unsupported span, $C_{L}$ is a coefficient that accounts for load position effect above the section centroid, and $C_{p}$ is a coefficient that accounts for the pre-buckling deformation effects. Starting with the variational expression defined in Section 5, the following section will develop approximate expressions for coefficients $C_{r}, C_{b}, C_{L}$, and $C_{p}$ for simply supported beams and then for cantilevers.

\subsection{Coefficients for simply supported beams}

\subsubsection{Partial twist coefficient}

Consider the beam to be laterally restrained but partially restrained against twist through two rotational springs with the constant stiffness $R$ at both ends. The beam is subjected to transverse loads acting at the section centroid (i.e., $V_{1}=0$ ). Under the applied loads, the bending moment distribution is assumed to be $M(x)$. It is required to formulate an expression for a coefficient $C_{r}$ that accounts for partial twist restraint while discarding 
the effects of pre-buckling deformations, i.e., $V_{3} \approx V_{4} \approx 0$. Starting with Eq. (1), while adding the internal strain energy stored in the end rotational springs $R / 2\left[\theta_{x}(0)\right]^{2}+R / 2\left[\theta_{x}(L)\right]^{2}$, the total potential energy $\pi$ takes the form of

$$
\begin{aligned}
\pi & =\frac{1}{2} \int_{0}^{L} E I_{y y} u^{\prime \prime}(x)^{2} d x+\frac{1}{2} \int_{0}^{L} G J \theta_{x}^{\prime}(x)^{2} d x+\frac{R}{2}\left[\theta_{x}(0)\right]^{2}+\frac{R}{2}\left[\theta_{x}(L)\right]^{2} \\
& +\int_{0}^{L} M(x) u^{\prime \prime}(x) \theta_{x}(x) d x
\end{aligned}
$$

For loading that is symmetric relative to the mid-span point, the lateral displacement $u(x)$ and angle of twist $\theta_{x}(x)$ are postulated to take the form

$u(x)=A \sin \left(\frac{\pi x}{L}\right) \quad \theta_{x}(x)=B+C \sin \left(\frac{\pi x}{L}\right)$

Equations (8)a-b meet the boundary conditions of the problem. The presence of the constant $B$ in Eq. (8)b stems from non-zero twist at both ends. From Eqs. (8)a-b by substituting into Eq. (7), and by evoking the stationary conditions $\partial \pi / \partial A=\partial \pi / \partial B=0$ and $\partial \pi / \partial C$ to obtain the neutral stability condition, one has

$$
\left[\begin{array}{ccc}
\frac{\pi^{4} E I_{y y}}{2 L^{3}} & -\frac{M_{0} I_{1}}{L} & -\frac{M_{0} I_{2}}{L} \\
-\frac{M_{0} I_{1}}{L} & 2 R & 0 \\
-\frac{M_{0} I_{2}}{L} & 0 & \frac{\pi^{2} G J}{2 L}
\end{array}\right]\left\{\begin{array}{l}
A \\
B \\
C
\end{array}\right\}=\left\{\begin{array}{l}
0 \\
0 \\
0
\end{array}\right\}
$$

where

$I_{1}=L \int_{0}^{L} \frac{M(x)}{M_{0}}\left[\left(\frac{\pi}{L}\right)^{2} \sin \left(\frac{\pi x}{L}\right)\right] d x, \quad I_{2}=L \int_{0}^{L} \frac{M(x)}{M_{0}}\left[\left(\frac{\pi}{L}\right)^{2} \sin ^{2}\left(\frac{\pi x}{L}\right)\right] d x$

$(10) \mathrm{a}-\mathrm{b}$

and $M_{0}$ is the maximum bending moment within the beam. Setting the determinant of the coefficients in Eq. (9) to zero, one recover the following expression for the critical moment

$$
M_{c r}=\bar{C}_{b} C_{r} M_{u}=\bar{C}_{b} C_{r} \frac{\pi}{L} \sqrt{E I_{y y} G J}
$$

in which the expression 
$\bar{C}_{b}=\pi^{2} / 2 I_{2}$

represents an approximate moment gradient coefficient, given that the postulated displacement functions in Eqs. (8)a-b are generally approximate, and $C_{r}$ is a partial twist restraint coefficient given by

$$
C_{r}=\sqrt{\frac{1}{1+\alpha \beta_{s}}}, \quad \alpha=\frac{G J / L}{R}, \quad \beta_{s}=\left(\frac{\pi I_{1}}{2 I_{2}}\right)^{2}
$$

Coefficient $C_{r}$ characterizes the reduction in critical moment capacity due to partial twist restraint provided by end brackets. Equations (13)a-c show that $C_{r}$ depends on the twisting stiffness ratio $\alpha$ and moment distribution through ratio $\beta_{s}$. The numerical values of $\beta_{s}$ as computed by Eq. (13)c are provided in Table 3 for common loading cases. Also, given in the table is the approximate moment gradient values for $\bar{C}_{b}$ as computed from the expression $\bar{C}_{b}=\pi^{2} / 2 I_{2}$. As expected, by setting $R \rightarrow \infty$ into Equation (13)a-b, one obtains $C_{r}=1.0$ and one recovers the critical moment expression $M_{c r 0}=\left(\pi \bar{C}_{b} / L\right) \sqrt{E I_{y y} G J}$ for a beam with full twist end restraint.

Table 3 Coefficients $\beta_{s}=\left(\pi I_{1} / 2 I_{2}\right)^{2}$ and $\bar{C}_{b}=\pi^{2} / 2 I_{2}$ for simply supported beams

\begin{tabular}{|c|c|c|c|c|}
\hline $\begin{array}{l}\text { Loading Case } \\
\quad(1)\end{array}$ & $\begin{array}{c}\text { Bending moment expression } M(x) \\
(2)\end{array}$ & $\begin{array}{l}\beta_{s} \\
(3)\end{array}$ & $\begin{array}{l}\bar{C}_{b} \\
(4)\end{array}$ & $\begin{array}{c}C_{b-F E A} \\
(5)\end{array}$ \\
\hline Am & $\begin{array}{l}M_{1}(x) \\
= \begin{cases}2(x / L) M_{0-M i d-P L} & 0 \leq x \leq L / 2 \\
2[1-(x / L)] M_{0-M i d-P L} & L / 2 \leq x \leq L\end{cases} \end{array}$ & 3.28 & 1.42 & 1.36 \\
\hline 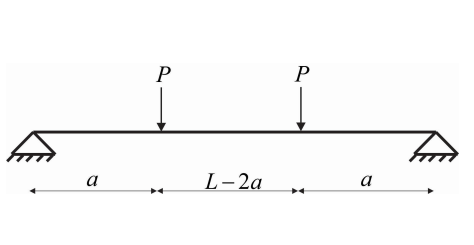 & $\begin{array}{l}M_{2}(x, a / L=1 / 3) \\
= \begin{cases}(L / a)(x / L) M_{0-2-P L} & 0 \leq x \leq a \\
M_{0-2-P L} & a \leq x \leq L-a \\
(L / a)[1-(x / L)] M_{0-2-P L} & L-a \leq x \leq L\end{cases} \end{array}$ & 3.42 & 1.12 & 1.09 \\
\hline मिभा & $M_{3}(x)=M_{1}(x)+M_{2}(x, a / L=1 / 4)$ & 3.45 & 1.21 & 1.19 \\
\hline $\mathrm{m}_{m}^{q} \mathrm{rm}$ & $M_{4}(x)=\frac{x(L-x) M_{0-U D L}}{(L / 2)^{2}}$ & 3.48 & 1.15 & 1.15 \\
\hline $\mathrm{C}^{M}$ & $M_{5}(x)=M$ & 4.00 & 1.00 & 1.00 \\
\hline
\end{tabular}


In principle, both expressions for $\bar{C}_{b}$ and $C_{r}$ are approximate since the displacement functions postulated in Eqs. (8)a-b are generally approximate. It is thus of interest to assess the effect of the approximation introduced in Eqs. (8)a-b on the results by comparing the predictions of Eq. (11) to solutions based on the present FEA. Thus, a representative reference case is considered for a simply supported beam with a $6 \mathrm{~m}$ span and an $80 \mathrm{~mm}$ wide $\mathrm{x} 570 \mathrm{~mm}$ deep cross-section subjected to a mid-span point load acting at the section mid-height. Material properties are $E=12800 \mathrm{MPa}$ and $G=E / 16$. The beam geometry is selected so that its capacity is governed by the elastic lateral torsional buckling strength according to the provisions of CAN-CSA O86-14. The critical moments are obtained from the present finite element formulated in Section 6. A mesh study has shown that eight elements are enough to attain convergence. The obtained critical moments $M_{c r-F E A}$ are then divided by the uniform critical moment $M_{u}=(\pi / L) \sqrt{E I_{y y} G J}$ to yield the moment gradient factor $C_{b-F E A}=M_{c r-F E A} / M_{u}$.

The numerical values for $\bar{C}_{b}$ in Column 4 of Table 3 slightly differ from $C_{b-F E A}$ in Column 5. For the examined loading cases, the $\bar{C}_{b} / C_{b-F E A}$ ratios were found to range from 1.00 to 1.04 with an average value of 1.02. For other non-symmetric loading cases, the displacement equations postulated in Eqs. (8)a-b will lead to drastically different moment gradient predictions and a more general approach is needed to quantify the moment gradient $C_{b}$ as will be discussed in subsequent sections.

Also, given the approximation introduced in Eqs. (8)a-b, it is of interest to assess the accuracy of the expression for $C_{r}$ as given in Eq. (13)a, intended to capture the reduction in critical moments. Towards this goal, the reference beam previously introduced is reconsidered while replacing the full torsional end restraints with partial twist restraints of stiffness $R$ varying from $50 \mathrm{kNm} / \mathrm{rad}$ to $200 \mathrm{kNm} / \mathrm{rad}$. The case of full twist restraint $R \rightarrow \infty$ was found to correspond to a predicted critical moment of $105.8 \mathrm{kNm}$ based on energy solution and $105.7 \mathrm{kNm}$ based on FEA solution developed under section 6 . For verification, a C3D8 model was built in ABAQUS (with a 150x60x4 mesh, along the span, height and width, respectively). The nine constants required to characterize the 
orthotropic behaviour of Douglas-fir wood species as taken from Ádány and Schafer [49] are the longitudinal modulus of elasticity $E_{L}=12,800 \mathrm{MPa}$; the shear moduli for stresses within the plane normal to the longitudinal direction, acting along radial and tangential directions $G_{L T}=G_{L R}=800 \mathrm{MPa} ; \quad$ and the remaining six constants $E_{R} / E_{L}=0.05, E_{T} / E_{L}=0.068, G_{R T} / E_{L}=0.007, v_{L R}=0.292, v_{L T}=0.449, v_{R T}=0.390$. The predicted critical moment of $M_{3 D-F E A}=103.2 \mathrm{MPa}$ is $2.4 \%$ lower than that predicted by the present finite element model. The critical moments predicted based on a modified form of Eq. (11), which replaces the approximate moment gradient $\bar{C}_{b}$ by the more accurate $C_{b-F E A}$, are compared to those based on the finite element solutions. Results in Table 4 show an excellent agreement between the prediction of Eq. (13)a for $C_{r}$ and those based on the FEA solution where the ratios of both solutions (Column 6) ranges from 0.98 to 1.00 , i.e., the expression for $C_{r}$ given in Eq. (13)a accurately characterizes the partial twist restraint at beam ends (Table 4).

Table 4 Effect of flexible twist end restraints on elastic critical moment of $80 \mathrm{mmx} 570 \mathrm{~mm}$ glulam beam $(\operatorname{span}=6 \mathrm{~m})$ under mid-span point load*

\begin{tabular}{|c|c|c|c|c|c|}
\hline \multirow{2}{*}{$\begin{array}{l}\text { Stiffness of twist end } \\
\text { restraint } \\
R(k N m / r a d) \\
\text { (1) }\end{array}$} & \multicolumn{3}{|c|}{ Present Solution } & \multicolumn{2}{|c|}{ Ratio } \\
\hline & $\begin{array}{l}\alpha \\
(2)\end{array}$ & $\begin{array}{l}C_{r} \\
(3)\end{array}$ & $\begin{array}{c}M_{\text {prop }}=C_{r} C_{b-F E A} M_{u} \\
\text { (4) }\end{array}$ & $\begin{array}{c}M_{F E A} \\
(5)\end{array}$ & $\begin{array}{c}M_{\text {prop }} / M_{F E A} \\
\text { (6) }\end{array}$ \\
\hline infinity & 0.0 & 1.000 & 105.8 & 105.7 & 1.00 \\
\hline 200 & 0.0591 & 0.915 & 96.8 & 97.6 & 0.99 \\
\hline 175 & 0.0676 & 0.905 & 95.8 & 96.6 & 0.99 \\
\hline 150 & 0.0788 & 0.891 & 94.3 & 95.2 & 0.99 \\
\hline 125 & 0.0946 & 0.874 & 92.5 & 93.5 & 0.99 \\
\hline 100 & 0.118 & 0.849 & 89.8 & 91.0 & 0.99 \\
\hline 75 & 0.158 & 0.812 & 85.9 & 87.3 & 0.98 \\
\hline 50 & 0.237 & 0.750 & 79.4 & 81.0 & 0.98 \\
\hline & & & & Average $=$ & 0.99 \\
\hline & & & Standa & eviation $=$ & 0.006 \\
\hline
\end{tabular}

$* C_{b}=C_{b-F E A}=1.36$ and $M_{u}=77.8 \mathrm{kNm}$

\subsubsection{Partial twist coefficient for different twist end restraints}

As the solutions in the previous section are limited to cases where the end twisting stiffness are equal, the present section extends the work to cases where end twist stiffness 
are different $R(0)=R_{1} \neq R(L)=R_{2}$. The simply supported beam under a mid-span point load in the previous section is revisited while assuming different values for coefficients $\alpha_{1}=G J / R_{1} L$ and $\alpha_{2}=G J / R_{2} L$. The critical moments are computed from the FEA and a partial twist coefficient $C_{r-F E A}$ (column 6 in Table 5) is obtained by dividing the critical moment by that of a beam with full twist restraint at both ends. The coefficients $C_{r 1}=1 / \sqrt{1+\beta_{s} \alpha_{1}}$ and $C_{r 2}=1 / \sqrt{1+\beta_{s} \alpha_{2}}$ are tabulated in Columns 3-4 of Table 5 while Column (5) provides the average values $\bar{C}_{r}=0.5\left(C_{r 1}+C_{r 2}\right)$. Column (7) provides the percentage difference $\left(\bar{C}_{r}-C_{r-F E A}\right) / C_{r-F E A}$. Close agreement between both solutions is observed as the percentage difference ranges from $-0.2 \%$ to $0.6 \%$ with an average value of $0.1 \%$, suggesting that adopting an average partial twist restraint $\bar{C}_{r}=0.5\left(C_{r 1}+C_{r 2}\right)$ leads to very good predictions. 
Table 5 Simply supported beam under mid-span point load with different partial twist restraints at both ends

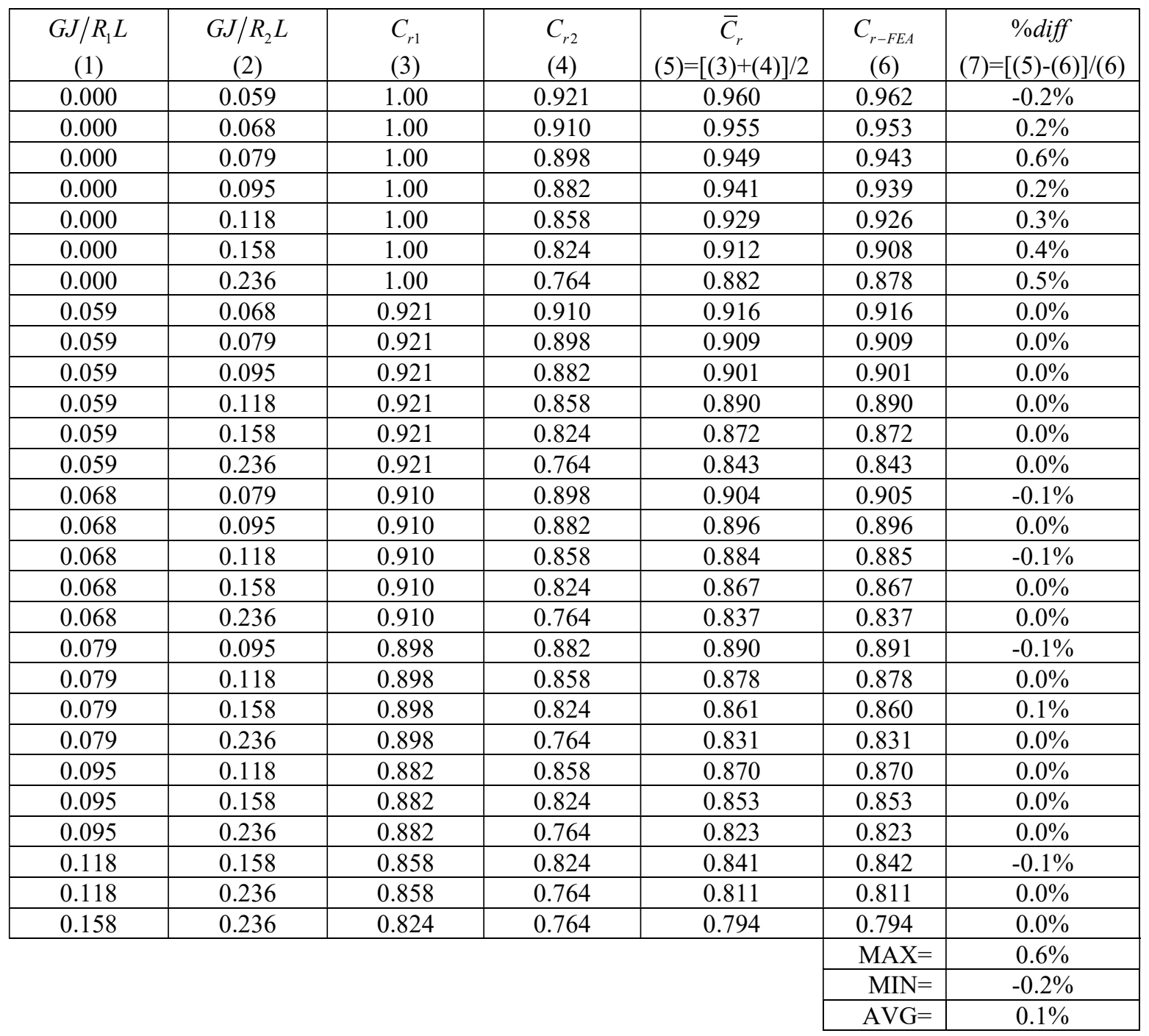

\subsubsection{Moment gradient coefficient}

Design standards for timber and steel members adopt one of two approaches to account for the moment gradient effects; (1) the effective length approach which have been adopted in ANSI/AWC-NDS-2015 [3], CAN-CSA O86-14 [1], and EN 1995-1-1: 2004 [30], and (2) the moment gradient approach have been used in CAN-CSA S16-14 [50], ANSI/AISC 360-16 [51], and AS-4100 [52]. For members with rectangular sections warping effects tend to be negligible, and both approaches become equivalent, while for other types of cross-sections (e.g., I-shaped), the moment gradient approach provides more consistent results [53]. Various standards have proposed different expressions for 
moment gradient factors for beam segments with lateral and torsional supports at both ends under general moment distributions. For example, the AFPA-TR14 [2] proposes the expression $C_{b-A F P A}=12.5 M_{\text {max }} / 3 M_{a}+4 M_{b}+3 M_{c}+2.5 M_{\text {max }}$, the CAN-CSA S16-14 [50] proposes the expression $C_{b-C A N}=4 M_{\max } / \sqrt{M_{\max }^{2}+4 M_{a}^{2}+3 M_{b}^{2}+4 M_{c}^{2}}$, while the Australian standards AS-4100 [52] proposes $C_{b-A U S}=1.7 M_{\max } / \sqrt{M_{a}^{2}+M_{b}^{2}+M_{c}^{2}}$, where $M_{a}=$ moment at quarter span, $M_{b}=$ moment at mid-span, $M_{c}=$ moment at three quarter span, and $M_{\max }=$ peak moment within the span. The Eurocode Guide does not provide a unified moment gradient equation, but instead gives load-specific moment gradient values $C_{b-E U R}$ for a number of practical cases (Tables 6.10 and 6.11 in Gardner and Nethercot [54]). The moment gradients based on the above four standards are provided in Table 6 for common loading cases; Uniformly Distributed Load (UDL), Mid-span Point Load (Mid-PL), 2 Point Loads (2-PL) at quarter and third-quarter points, and linear bending moments where the end moment ratio $\psi$ (Fig. 2) varies from $\psi=+1$ to $\psi=-1$. To assess the accuracy of the various Moment Gradient Factor (MGF) equations, a comparison with moment gradients predicted by the finite element analysis is provided. The critical moment $M_{c r-F E A}$ obtained for a simply supported beam with an $8 \mathrm{~m}$ span and $80 \mathrm{~mm} \times 570 \mathrm{~mm}$ cross-section is provided in Table 6 and the corresponding moment gradient as calculated from $C_{b-F E A}=M_{c r-F E A} / M_{u}$. When obtaining $M_{c r-F E A}$, the prebuckling deformation and load height effects have been omitted by discarding the terms $V_{1}, V_{3}, V_{4}$ from the functional in Eq. (1).

As observed, the best agreement with FEA predictions is obtained for the Australian Steel Standards where the moment gradient ratio lies between 0.94 and 1.08, with an average difference of 0.99 . The comparison suggests the adoption of the AS-4100 moment gradient expression $C_{b-A U S}=1.7 M_{\max } / \sqrt{M_{a}^{2}+M_{b}^{2}+M_{c}^{2}}$ given its accuracy and simplicity (as it involves three sampling points compared to four sampling points in other MFG equations). 

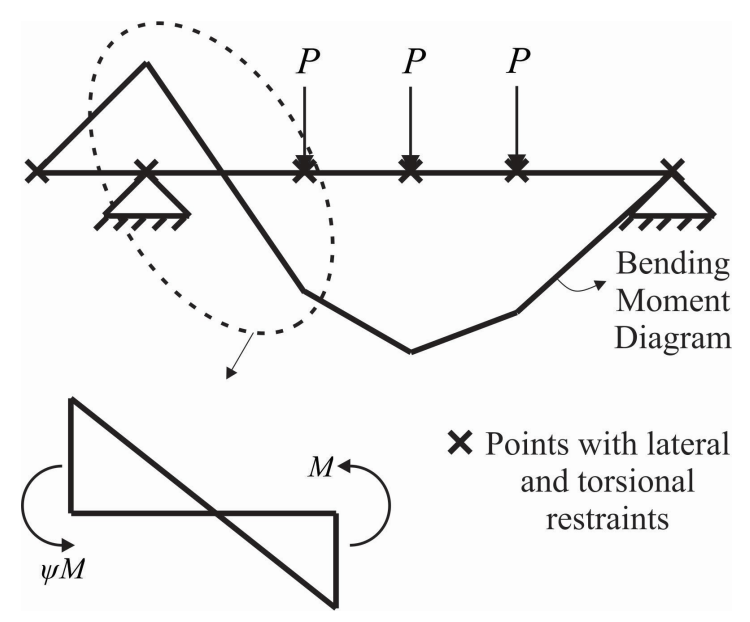

Fig. 2 Bending moment diagram and definition of end moment ratio $\psi$

Table 6 Summarized MGF for an $80 \mathrm{~mm} 570 \mathrm{~mm}$ rectangular section of $8 \mathrm{~m}$ span under various

loading cases

\begin{tabular}{|c|c|c|c|c|c|c|c|c|c|}
\hline \multirow[b]{2}{*}{$\begin{array}{c}\text { Bending } \\
\text { moment } \\
\text { pattern }\end{array}$} & \multicolumn{5}{|c|}{ Moment Gradient Factors } & \multicolumn{4}{|c|}{ Moment gradient factor/FEA } \\
\hline & $\begin{array}{l}\text { FEA } \\
(1)\end{array}$ & $\begin{array}{c}\text { Eurocode } \\
\text { Guide } \\
\text { (steel) } \\
\text { MFG } \\
(2)\end{array}$ & $\begin{array}{c}\text { AFPA } \\
\text { Equation } \\
\text { (3) }\end{array}$ & $\begin{array}{l}\text { Australian } \\
\text { Steel Code } \\
\text { Equation } \\
\text { (4) }\end{array}$ & $\begin{array}{c}\text { Canadian } \\
\text { Steel } \\
\text { Code } \\
\text { Equation } \\
\text { (5) }\end{array}$ & $\begin{array}{c}(6)= \\
(1) /(2)\end{array}$ & $\begin{array}{c}(7)= \\
(1) /(3)\end{array}$ & $\begin{array}{c}(8)= \\
(1) /(4)\end{array}$ & $\begin{array}{c}(9)= \\
(1) /(5)\end{array}$ \\
\hline$\psi=1$ & 1.00 & 1.00 & 1.00 & 1.00 & 1.00 & 1.00 & 1.00 & 1.00 & 1.00 \\
\hline$\psi=0.75$ & 1.15 & 1.14 & 1.11 & 1.12 & 1.13 & 1.01 & 1.04 & 1.03 & 1.02 \\
\hline$\psi=0.5$ & 1.32 & 1.32 & 1.25 & 1.30 & 1.29 & 1.00 & 1.06 & 1.02 & 1.02 \\
\hline$\psi=0.25$ & 1.53 & 1.56 & 1.43 & 1.53 & 1.50 & 0.98 & 1.07 & 1.00 & 1.02 \\
\hline$\psi=0$ & 1.78 & 1.88 & 1.67 & 1.82 & 1.75 & 0.95 & 1.07 & 0.98 & 1.02 \\
\hline$\psi=-0.25$ & 2.07 & 2.28 & 2.00 & 2.16 & 2.03 & 0.91 & 1.04 & 0.96 & 1.02 \\
\hline$\psi=-0.5$ & 2.36 & 2.70 & 2.17 & 2.48 & 2.29 & 0.87 & 1.09 & 0.95 & 1.03 \\
\hline$\psi=-0.75$ & 2.62 & 2.93 & 2.22 & 2.59 & 2.41 & 0.89 & 1.18 & 1.01 & 1.09 \\
\hline$\psi=-1$ & 2.59 & 2.75 & 2.27 & 2.40 & 2.31 & 0.94 & 1.14 & 1.08 & 1.12 \\
\hline UDL & 1.15 & 1.13 & 1.14 & 1.17 & 1.13 & 1.02 & 1.01 & 0.98 & 1.02 \\
\hline Mid-PL & 1.36 & 1.37 & 1.32 & 1.39 & 1.27 & 0.99 & 1.03 & 0.98 & 1.07 \\
\hline 2-PL & 1.10 & 1.05 & 1.14 & 1.17 & 1.13 & 1.05 & 0.96 & 0.94 & 0.97 \\
\hline \multicolumn{6}{|r|}{ Average $=$} & 0.97 & 1.06 & 0.99 & 1.03 \\
\hline \multicolumn{6}{|c|}{ Standard Deviation= } & 0.06 & 0.06 & 0.04 & 0.04 \\
\hline
\end{tabular}




\subsubsection{Load height coefficient}

Consider a simply supported beam laterally and torsionally restrained at both ends. The beam is subjected to a UDL $q$ acting at a distance $y_{q}$ above the centroid, and a series of $i=1,2, \ldots n_{p}$ equidistant point loads of equal magnitude $P$ located at distances $x_{i}$ from the left support, and acting at a height $y_{p}$ above the section centroid. The bending moment $M(x)$ corresponding to the superposition of the UDL $q$ and the point loads $P$ has a peak value $M_{0}$. It is required to formulate an expression for a coefficient $C_{L}$ that accounts for load height effect while neglecting the effects of pre-buckling deformations. The total potential energy in Eq. (1), while retaining the internal strain energy terms $U_{1}$, $U_{2}$, the destabilizing terms $V_{1}$ due to bending moments, and $V_{2}$ due to load height, and omitting the terms related to pre-buckling deformations $\left(V_{3} \approx V_{4} \approx 0\right)$, takes the form of

$$
\begin{aligned}
\pi & =\frac{1}{2} \int_{0}^{L} E I_{y y} u^{\prime \prime}(x)^{2} d x+\frac{1}{2} \int_{0}^{L} G J \theta_{x}^{\prime}(x)^{2} d x+\int_{0}^{L} M(x) u^{\prime \prime}(x) \theta_{x}(x) d x \\
& +\frac{1}{2} q \int_{0}^{L} y_{q} \theta_{x}(x)^{2} d x+\frac{1}{2} P y_{p} \sum_{i=1}^{n_{p}} \theta_{x i}(x)^{2}
\end{aligned}
$$

where the last term of Eq. (14), incorporates the additional destabilizing effect due to the point load being offset from the section centroid. The lateral displacement $u(x)$ and the angle of twist $\theta_{x}(x)$ are postulated to take the form

$u(x)=A \sin \left(\frac{\pi x}{L}\right), \quad \theta_{x}(x)=B \sin \left(\frac{\pi x}{L}\right)$

From Eqs. (15)a-b, by substituting into Eq. (14) and evoking the stationary conditions $\partial \pi / \partial A=\partial \pi / \partial B=0$, the following conditions of neutral stability can be written:

$$
\left[\begin{array}{c:c}
\frac{\pi^{4} E I_{y y}}{2 L^{3}} & \frac{-M_{0} I_{2}}{L} \\
\hdashline \frac{-M_{0} I_{2}}{L} & \frac{\pi^{2} G J}{2 L}-\frac{L}{2} q y_{q}-P y_{p} \sum_{i=1}^{n_{p}}\left[\sin \left(\frac{\pi x_{i}}{L}\right)\right]^{2}
\end{array}\right]\left\{\begin{array}{l}
A \\
B
\end{array}\right\}=\left\{\begin{array}{l}
0 \\
0
\end{array}\right\}
$$

where it is recalled that $M_{0}$ is the maximum bending moment and $I_{2}$ has been defined in Eq. (10)b. In terms of moment gradient factor, it can also be expressed as 
$I_{2}=\pi^{2} / 2 C_{b}$

In Eq. (16), Point loads $P$ and UDL $q$ need to be expressed in terms of the peak bending moment $M_{0}$, as given in Table 7 for common loading case. By setting the determinant of the coefficient matrix in Eq. (16) to zero, one obtains the critical moment as

$$
M_{c r}=\frac{E I_{y y} \pi^{3}}{4 I_{2}^{2} L}\left\{\sqrt{\left[4 \frac{G J}{E I_{y y}} I_{2}^{2}+\left[\varphi\left(M_{0}\right)\right]^{2}\right]}-\varphi\left(M_{0}\right)\right\}
$$

where

$$
\varphi\left(M_{0}\right)=\pi\left\{\frac{P y_{p}}{M_{0}}\left[\sum_{i=1}^{n_{p}} \sin ^{2}\left(\frac{\pi x_{i}}{L}\right)\right]+\frac{q L y_{q}}{2 M_{0}}\right\}
$$

For the special case where all loads are applied at the section centroidal axis, $\varphi\left(M_{0}\right)=0$, and Eq. (18) reverts to the critical moment expression

$$
M_{c r 0}=\left(\pi^{3} / 2 I_{2} L\right) \sqrt{E I_{y y} G J}
$$

By dividing Eq. (18) by $M_{c r 0}$, one obtains the sought load height coefficient

$$
C_{L}=\frac{M_{c r}}{M_{c r 0}}=\sqrt{1+\eta^{2}}-\eta
$$

where $\eta=\left[\varphi\left(M_{0}\right) / 2 I_{2}\right] \sqrt{E I_{y y} / G J}$. From Eq. (19), by substituting $\varphi\left(M_{0}\right)$ into the expression for $\eta$, one obtains

$$
\eta=\frac{\pi}{2 I_{2}}\left\{\frac{P y_{p}}{M_{0}}\left[\sum_{i=1}^{n_{p}} \sin ^{2}\left(\frac{\pi x_{i}}{L}\right)\right]+\frac{q L y_{q}}{2 M_{0}}\right\} \sqrt{\frac{E I_{y y}}{G J}}
$$

For the special case of uniformly distributed load applied at a height $y_{q}$, expression (22) leads to $\eta=1.46\left(y_{q} / L\right) \sqrt{E I_{y y} / G J}$. When the load is applied at the top face $y_{q}=h / 2, \eta$ takes the form $\eta=1.46(h / 2 L) \sqrt{E I_{y y} / G J}$, which compares to $\eta=\left(k_{A F P A} h / 2 L\right) \sqrt{E I_{y y} / G J}=1.44(h / 2 L) \sqrt{E I_{y y} / G J}$ reported in AFPA-TR14. In general, for top face loading, the present solution will take the form $\eta=(k h / 2 L) \sqrt{E I_{y y} / G J}$, which is similar to that reported in the AFPA $\eta=\left(k_{A F P A} h / 2 L\right) \sqrt{E I_{y y} / G J}$. A comparison 
between $k$ and $k_{A F P A}$ for other loading cases of interest is provided in Table 7. Unlike the $k_{A F P A}$ values that are specific to certain types of loading applied at the top face, Eq. (22) provides a basis to determine $k$ for more general loading applied at any height $y_{q}$.

Table 7 Load height parameter value $k$ for top face loading

\begin{tabular}{|c|c|c|c|}
\hline Loading Cases & $M_{0}$ & $\begin{array}{l}k \text { based on } \\
\text { present study }\end{array}$ & $\begin{array}{c}k_{A F P A} \text { based } \\
\text { on AFPA }\end{array}$ \\
\hline$C_{A}^{M}$ & $M$ & N/A & N/A \\
\hline Arm & $\frac{q L^{2}}{8}$ & 1.46 & 1.44 \\
\hline 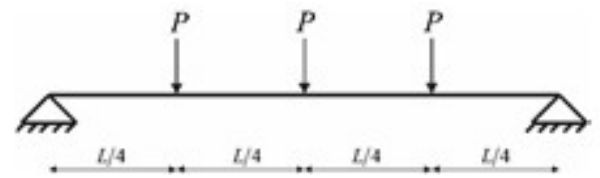 & $\frac{P L}{2}$ & 1.54 & 1.45 \\
\hline 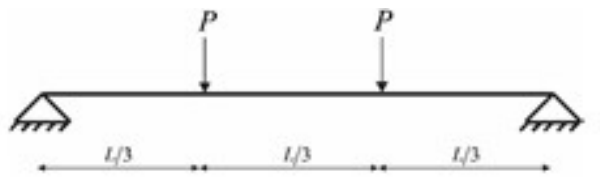 & $\frac{P L}{3}$ & 1.60 & 1.63 \\
\hline 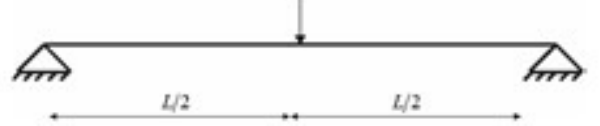 & $\frac{P L}{4}$ & 1.81 & 1.72 \\
\hline
\end{tabular}

Consider the reference beam previously defined under two loading scenarios (1) midspan PL and (2) UDL, both applied at the beam top face. The critical moment predictions based on the expression $M_{c r}=C_{b} C_{L} M_{u}$ where $C_{b}=C_{b-F E A}$ and $C_{L}$ is based on Eq. (21) are compared with FEA solutions (Table 8). Excellent agreement is attained between FEA results and the proposed equation. For the case of mid-span PL, the ratio between both predictions as provided in Column 6 ranges from 1.01 to 1.03 with an average of 1.02 and for the UDL, the ratio varies from 1.00 to 1.01 with an average of 1.00 (Column $10)$. 
Table 8 Summary of results for interaction between moment gradient factor and load height effects

\begin{tabular}{|c|c|c|c|c|c|c|c|c|c|}
\hline \multirow[b]{2}{*}{$\begin{array}{l}\mathrm{L}(\mathrm{m}) \\
(1)\end{array}$} & \multirow[b]{2}{*}{$\begin{array}{c}M_{u} \\
(k N m) \\
(2)\end{array}$} & \multicolumn{4}{|c|}{ Mid-span PL } & \multicolumn{4}{|c|}{ UDL } \\
\hline & & $\begin{array}{l}C_{L} \\
\text { (3) }\end{array}$ & $\begin{array}{c}M_{c r}=C_{b} C_{L} M_{u} \\
\text { (4) }\end{array}$ & $\begin{array}{c}M_{F E A} \\
(k N m) \\
(5)\end{array}$ & $\begin{array}{c}(6)= \\
(4) /(5)\end{array}$ & $\begin{array}{l}C_{L} \\
\text { (7) }\end{array}$ & $\begin{array}{c}M_{c r}=C_{b} C_{L} M_{u} \\
\text { (8) }\end{array}$ & $\begin{array}{c}M_{F E A} \\
(k N m) \\
(9)\end{array}$ & $\begin{array}{l}(10)= \\
(8) /(9)\end{array}$ \\
\hline 6 & 77.8 & 0.84 & 88.9 & 86.7 & 1.03 & 0.87 & 77.8 & 77.4 & 1.01 \\
\hline 7 & 66.7 & 0.86 & 78.0 & 76.5 & 1.02 & 0.88 & 67.5 & 67.7 & 1.00 \\
\hline 8 & 58.4 & 0.87 & 69.1 & 68.4 & 1.01 & 0.90 & 60.4 & 60.2 & 1.00 \\
\hline 9 & 51.9 & 0.89 & 62.8 & 61.8 & 1.02 & 0.91 & 54.3 & 54.1 & 1.00 \\
\hline 10 & 46.7 & 0.90 & 57.2 & 56.4 & 1.01 & 0.92 & 49.4 & 49.2 & 1.00 \\
\hline \multicolumn{5}{|c|}{ Average $=$} & 1.02 & \multicolumn{3}{|c|}{ Average $=$} & 1.00 \\
\hline \multicolumn{5}{|c|}{ Standard Deviation $=$} & 0.008 & \multicolumn{3}{|c|}{ Standard Deviation= } & 0.004 \\
\hline
\end{tabular}

$* C_{b}=C_{b-F E A}=1.36$ for mid-span PL and $C_{b}=C_{b-F E A}=1.15$ for UDL

It is of interest to note that for mid-span loading, the moment gradient coefficient ( Section 8.1.3) and load height coefficient (Section 8.1.4) yield the following expression for the critical moment

$$
M_{c r}=1.36\left\{\sqrt{1+\left(1.81 y_{g} / k_{y} L \sqrt{E I_{y y} / G J}\right)^{2}}-\left(1.81 y_{g} / k_{y} L \sqrt{E I_{y y} / G J}\right)\right\} \frac{\pi}{L} \sqrt{E I_{y y} G J}
$$

A nearly identical can be obtained after omitting the mono-symmetry and warping effects contributions in Balaz and Kolekova [12] where in lieu of the 1.36 factor above Balaz and Kolekova provide 1.35, and instead of the 1.81 factor, they provide1.74. Likewise, for UDL, the present solution provides the expression

$$
M_{c r}=1.15\left\{\sqrt{1+\left(1.46 y_{g} / k_{y} L \sqrt{E I_{y y} / G J}\right)^{2}}-\left(1.46 y_{g} / k_{y} L \sqrt{E I_{y y} / G J}\right)\right\} \frac{\pi}{L} \sqrt{E I_{y y} G J}
$$

which nearly coincides with the Balaz and Kolekova [12] expressions, where the 1.15 is replaced by 1.13 and the 1.46 is replaced by 1.44 .

\subsubsection{Pre-buckling coefficient}

As discussed after Eq. (5), it is required to develop an expression for a coefficient $C_{p}$ that characterizes the influence of pre-buckling deformation effects for a simply supported beam, both laterally and torsionally, under general loading. When developing the required expression, the loads are assumed to act at the centroidal axis, i.e., $V_{1} \approx 0$, while all other terms $\left(U_{1}, U_{2}, V_{2}, V_{3}, V_{4}\right)$ are retained. The resulting total potential energy expression in Eq. (1) takes the form 


$$
\begin{aligned}
\pi=\frac{1}{2} \int_{0}^{L} E I_{y y} u^{\prime \prime}(x)^{2} d x+\frac{1}{2} \int_{0}^{L} G J \theta_{x}^{\prime}(x)^{2} d x \\
\quad+\frac{1}{2} \int_{0}^{L}\left\{2 \lambda M(x)\left(1-\frac{I_{y y}}{I_{z z}}\right) u^{\prime \prime}(x) \theta_{x}(x)-\lambda^{2} \frac{M^{2}(x)}{E I_{z z}}\left(1-\frac{I_{y y}}{I_{z z}}\right) \theta_{x}(x)^{2}\right\} d x
\end{aligned}
$$

Starting with the assumed displacement functions introduced in Eqs. (15)a-b, substituting into Eq. (23), and evoking the stationary conditions $\partial \pi / \partial A=\partial \pi / \partial B=0$, one obtains

$$
\left[\begin{array}{cc}
\frac{\pi^{4} E I_{y y}}{2 L^{3}} & \frac{-M_{0}}{L}\left(1-\frac{I_{y y}}{I_{z z}}\right) I_{2} \\
\frac{-M_{0}}{L}\left(1-\frac{I_{y y}}{I_{z z}}\right) I_{2} & \frac{\pi^{2} G J}{2 L}-\frac{L M_{0}^{2}}{E I_{z z}}\left(1-\frac{I_{y y}}{I_{z z}}\right) \chi
\end{array}\right]\left\{\begin{array}{l}
A \\
B
\end{array}\right\}=\left\{\begin{array}{l}
0 \\
0
\end{array}\right\}
$$

where $\chi=(1 / L) \int_{0}^{L} M(x)^{2} / M_{0}^{2}[\sin (\pi x / L)]^{2} d x$ and $M_{0}$ has been defined as the peak moment. Setting to zero the determinant of the matrix in Eq. (24) yields the critical moment equation

$$
M_{c r}=\frac{\pi^{3} \sqrt{E I_{y y} G J}}{l \sqrt{2\left(1-\frac{I_{y y}}{I_{z z}}\right)\left[\pi^{4} \frac{I_{y y}}{I_{z z}} \chi+2 I_{2}^{2}\left(1-\frac{I_{y y}}{I_{z z}}\right)\right]}}
$$

For the special case where pre-buckling deformation effects are neglected, one has $\chi=0$ and $\left[1-\left(I_{y y} / I_{z z}\right)\right]=1$. In such a case, Eq. (25) reverts to the critical moment expression $M_{c r 0}$ as given by Eq. (20). Dividing Eq. (25) by $M_{c r 0}$, one obtains the sought prebuckling deformation coefficient $C_{p}$, which takes the form

$$
C_{p}=\frac{M_{c r}}{M_{c r 0}}=\frac{1}{\sqrt{\left(1-I_{y y} / I_{z z}\right)\left(1+\delta_{s} I_{y y} / I_{z z}\right)}}
$$

where $\delta_{s}=\pi^{4} \chi / 2 I_{2}^{2}-1$ is a dimensionless constant that depends on the load distribution and is provided in Table 9 for common loading cases. The pre-buckling coefficient in (26) is numerically very close to the value $1 / \sqrt{1-I_{y y} / I_{z z}}=1 / \sqrt{1-(b / d)^{2}}$ reported in Hooley and Madsen [4] and AFPA-TR14 [2]. The development of Eq. (26) is limited to the case of full twist end restraints. It is thus required to assess its applicability for the 
case of partial twist restraint through comparison with FEA predictions. A $12 \mathrm{~m}$ span beam is considered with a $215 \mathrm{~mm} \times 570 \mathrm{~mm}$ cross-section under uniform bending moment. Partial twist end restraints with stiffness values $R$ varying from $50 \mathrm{kNm} / \mathrm{rad}$ to 1000 $\mathrm{kNm} / \mathrm{rad}$ are considered. Table 10 provides the dimensionless twisting stiffness ratio $\alpha=G J / L R$ and the corresponding partial twist coefficient $C_{r}$ as given by Eq. (13)a. The results show that Eq. (26) slightly overestimates the critical moment for the case of partial twist restraint, as the ratio of the two solutions ranges from 1.01 at $\alpha=0.96$ (Column (6) of Table 10) to 1.09 at $\alpha=1.92$ with an average value ratio of 1.03 .

Table 9 Pre-buckling deformation coefficient $C_{p}=1 / \sqrt{\left(1-I_{y y} / I_{z z}\right)\left(1+\delta_{s} I_{y y} / I_{z z}\right)}$ for various loading

\begin{tabular}{|c|c|}
\hline \multicolumn{2}{|l|}{ cases } \\
\hline Loading Cases & $\delta_{s}$ \\
\hline$\left(\mathrm{C}_{\mathrm{m}}^{M} \quad\right.$ 命 & 0 \\
\hline$\rightarrow$ & $3.18 \times 10^{-2}$ \\
\hline 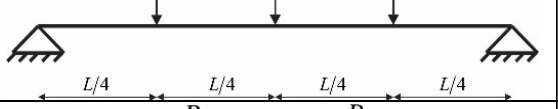 & $3.58 \times 10^{-2}$ \\
\hline मित $\begin{array}{llll}L / 3 & & & \\
L & L / 3 & \end{array}$ & $4.01 \times 10^{-2}$ \\
\hline मित $L_{L / 2} \quad 1 \quad$ मिते & $8.56 \times 10^{-2}$ \\
\hline
\end{tabular}


Table 10 Effect of partial twist end restraints on elastic critical moment of $215 \mathrm{mmx570mm} \mathrm{glulam}$ beam $(\operatorname{span}=12 \mathrm{~m})$

\begin{tabular}{|c|c|c|c|c|c|}
\hline \multirow{3}{*}{$\begin{array}{c}\text { Stiffness of end } \\
\text { rotational restraint } \\
(1) R(k N m / r a d)\end{array}$} & $\alpha=G J / L R$ & $C_{r}$ & $M_{\text {present }}=C_{r} C_{p} M_{u}$ & $M_{F E A}$ & \multirow{2}{*}{$M_{\text {present }} / M_{\text {FEA }}$} \\
\cline { 2 - 5 } & $(2)$ & $(3)$ & $(4)$ & $(5)$ & \\
\hline 50 & & & & & \\
\hline 100 & 1.92 & 0.339 & 253 & 232 & 1.09 \\
\hline 200 & 0.960 & 0.455 & 340 & 316 & 1.07 \\
\hline 300 & 0.480 & 0.585 & 437 & 415 & 1.05 \\
\hline 400 & 0.320 & 0.662 & 494 & 476 & 1.04 \\
\hline 500 & 0.240 & 0.714 & 533 & 518 & 1.03 \\
\hline 600 & 0.192 & 0.752 & 561 & 549 & 1.02 \\
\hline 700 & 0.160 & 0.781 & 583 & 572 & 1.02 \\
\hline 800 & 0.137 & 0.804 & 600 & 591 & 1.02 \\
\hline 900 & 0.120 & 0.822 & 613 & 606 & 1.01 \\
\hline 1000 & 0.107 & 0.837 & 625 & 618 & 1.01 \\
\hline & 0.096 & 0.850 & 634 & 629 & 1.01 \\
\hline & & & & Average & 1.03 \\
\hline
\end{tabular}

$* C_{p}=1.08$ and $M_{u}=691 \mathrm{kNm}$

Fig. 3 shows the pre-buckling coefficient $C_{p}$ as predicted by the expression $C_{p}=1 / \sqrt{\left(1-I_{y y} / I_{z z}\right)\left(1+\delta_{s} I_{y y} / I_{z z}\right)}$ versus $I_{y y} / I_{z z}$ for a simply supported beam with a $570 \mathrm{~mm}$ deep cross-section and a width $b$ varying from $80 \mathrm{~mm}$ to $250 \mathrm{~mm}$ for five loading cases provided in Table 9. The solution based on the FEA solution is provided for comparison. Excellent agreement is observed between the predictions of the proposed equation for $C_{p}$ and those based on the finite element formulation where the ratio of $C_{p}$ based on present study as the $C_{p}$ ratio based on FEA to that based on the equation varies from 0.99 to 1.00 for all loading case considered. 


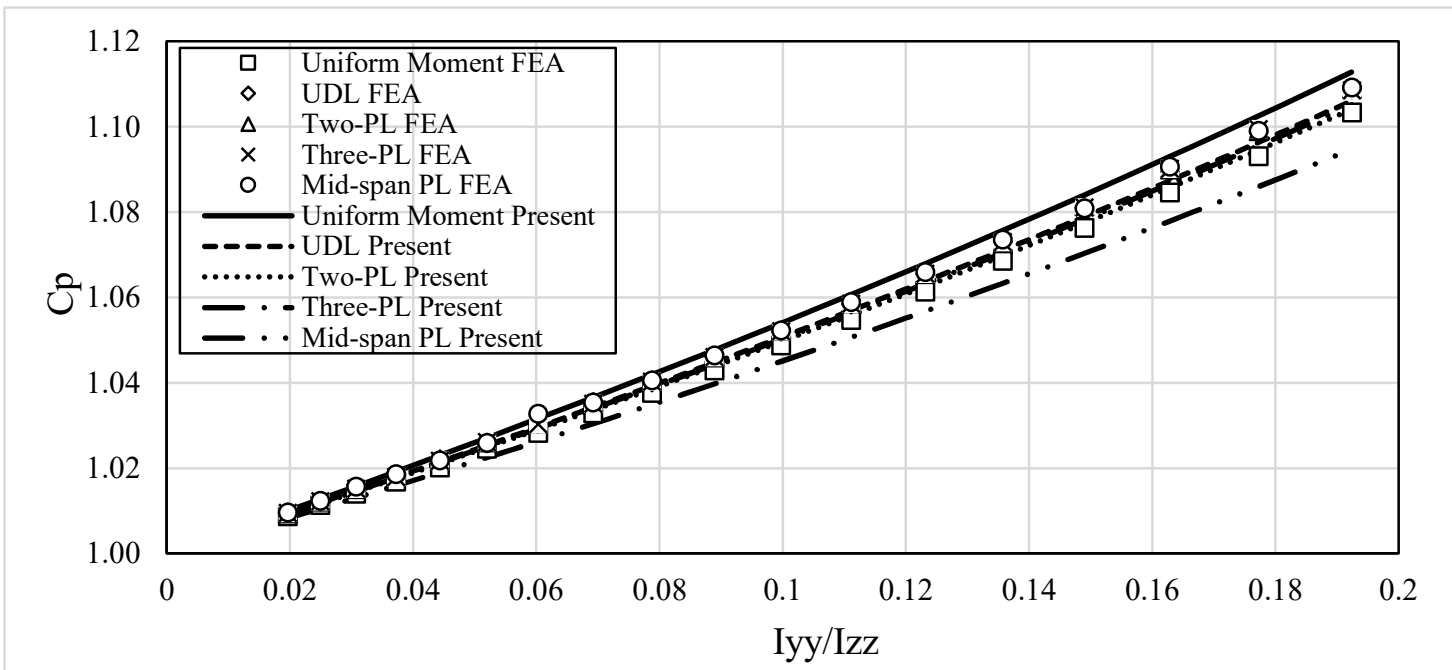

Fig. 3 Pre-buckling coefficient versus $I_{y y} / I_{z z}$ for various loading cases

\subsection{Coefficients for cantilevers}

\subsubsection{Moment gradient coefficient}

A cantilever with an $80 \mathrm{mmx} 570 \mathrm{~mm}$ cross-section is fully fixed at the root and entirely free at the tip. Two loading cases are considered (1) a point load at the tip, and (2) a uniformly distributed load applied at section mid-height. Span is to vary from $L=2 m$ to $L=12 \mathrm{~m}$. The critical moment $M_{c r-F E A}$ is obtained from the finite element solution and the moment gradient $C_{b-F E A}$ is computed from the relation $M_{c r-F E A}=\left(C_{b-F E A} \pi / L\right) \sqrt{E I_{y y} G J}$. Irrespective of the $\operatorname{span} L$, the moment gradients thus computed are 1.28 for the point load and 2.05 for the uniformly distributed load cases. In comparison, in EN 1995-1-1: 2004 [30], the critical moment $M_{c r-E N}=\left(\pi / L_{e}\right) \sqrt{E I_{y y} G J}$ is defined based on the effective length $L_{e}$ which is given as $L_{e}=0.8 L$ for tip loading and $L_{e}=0.5 L$ for UDL. These effective lengths correspond to a moment gradient $C_{b}=L / L_{e}$ of 1.25 for point load and 2.00 for UDL, which are close to those based on the present study. 


\subsubsection{Partial twist coefficient}

The solution provided in the previous section assumes full torsional fixity at the cantilever root, a condition that is difficult to realize in practice owing to the torsional flexibility of the connection at the root of the cantilever. In order to account for the torsional flexibility at the connection, the root of the cantilever is considered fully restrained in the lateral direction but partially restrained against twist through a partial twisting spring with stiffness of $R(0)$. For a given moment distribution $M(x)$ with a peak moment $M_{0}$, the buckling displacement fields are approximated by

$\theta_{x}(x)=A+B\left[1-\cos \left(\frac{\pi x}{2 L}\right)\right], \quad u(x)=C\left[1-\cos \left(\frac{\pi x}{2 L}\right)\right]$

By substituting into Eq. (7), setting $R(L)=0$, and evoking the neutral stability condition, one obtains $M_{c r}=C_{r} \bar{C}_{b} M_{u}$ where $C_{r}=1 / \sqrt{\left(1+\beta_{c} \alpha\right)}, \alpha=G J / R L, \beta_{c}=32\left(I_{3} / \pi\right)^{2} \bar{C}_{b}^{2}$, $\bar{C}_{b}=\pi^{2} / 16 I_{4}$, and $M_{u}=(\pi / L) \sqrt{E I_{y y} G J}$. In the previous equation, the following integrals have been introduced.

$$
I_{3}=L \int_{0}^{L} \frac{M(x)}{M_{0}}\left[-\left(\frac{\pi}{2 L}\right)^{2} \cos \left(\frac{\pi x}{2 L}\right)\right] d x, I_{4}=L \int_{0}^{L} \frac{M(x)}{M_{0}}\left[\left(\frac{\pi}{2 L}\right)^{2} \cos \left(\frac{\pi x}{2 L}\right)\right]\left[1-\cos \left(\frac{\pi x}{2 L}\right)\right] d x
$$

(28)a-b

Considering the case of point load acting at the cantilever tip, the moment distribution is $M(x)=M_{0}[1-(x / L)]$ which yield $I_{3}=1, I_{4}=0.133, \beta_{c}=3.24 \bar{C}_{b}^{2}$, and $\bar{C}_{b}=4.63$. For a uniformly distributed load, the moment distribution is $M(x)=\left[(L-x)^{2} / L^{2}\right] M_{0}$, which yields $I_{3}=0.727, I_{4}=0.0655, \beta_{c}=1.71 \bar{C}_{b}^{2}$, and $\bar{C}_{b}=9.41$. It is noted that the moment gradient factors $\bar{C}_{b}=4.63$ and $\bar{C}_{b}=9.41$ predicted by the energy solution are significantly higher than the FEA predictions in section 8.2.1. This is because the displacement functions postulated in Eqs. (27)a-b are approximate and do not satisfy the natural boundary conditions at the free end. Thus, the values of $C_{b}$ will be used instead of $\bar{C}_{b}$ in the following steps. In contrast, the expressions for $\beta_{c}$ and $C_{r}$ provide reliable approximations for the partial twist effect in comparison to FEA predictions, provided 
that they are based on coefficients $C_{b}$ as obtained in Section 8.2.1 as will be shown in the following. Consider a $2 \mathrm{~m}$ span cantilever with an $80 \mathrm{~mm} \times 570 \mathrm{~mm}$ cross-section, with a partial twist restraint at the root of stiffness $R$ varying from $50-200 \mathrm{kNm} / \mathrm{rad}$. Material properties are $E=12800 \mathrm{MPa}$ and $G=E / 16$. Two loading cases are considered: (1) a point load acting at the tip, and (2) a UDL. Loads are applied at the section centroid in both cases. A comparison is made between the coefficient of partial twist restraint $C_{r}$ based on the equations $C_{r}=1 / \sqrt{\left(1+\beta_{c} \alpha\right)}, \beta_{c}=3.24 C_{b}^{2}$, and $C_{b}=C_{b-F E A}=1.28$ to those predicted by the FEA as obtained by dividing the critical moment of a cantilever with a flexible twist end restraint of stiffness $R$ to that of a cantilever with a rigid twist end restraint for the case of tip load (Table 11). A similar comparison for UDL is provided in (Table 12) for UDL based on $C_{r}=1 / \sqrt{\left(1+\beta_{c} \alpha\right)}, \beta_{c}=1.71 \bar{C}_{b}^{2}$, and $C_{b}=C_{b-F E A}=2.05$. Excellent agreement is obtained between $C_{r}$ based on FEA and the proposed equation based on energy solutions where $C_{r}$ (present $) / C_{r}(F E A)$ ratio varies from 0.97 to 0.99 with an average of 0.98 for the case of tip point load, and varies from 1.01 to 1.05 with an average of 1.02 for UDL.

Table 11 Effect of flexible twist end restraint on elastic critical moment for $2 \mathrm{~m}$ span Glulam cantilever with $80 \mathrm{~mm} \times 570 \mathrm{~mm}$ cross-section under tip point load

\begin{tabular}{|c|c|c|c|c|}
\hline \multirow[b]{2}{*}{$\begin{array}{c}\text { Stiffness of twist end } \\
\text { restraint } \\
R(k N m / R a d) \\
\text { (1) }\end{array}$} & \multicolumn{2}{|c|}{ Present Solution } & \multirow[b]{2}{*}{$\begin{array}{l}\text { Finite element } \\
\qquad C_{r-F E A} \\
(4)\end{array}$} & \multirow[b]{2}{*}{$\begin{array}{c}\text { Ratio } C_{r} / C_{r-F E A} \\
\text { (5) }\end{array}$} \\
\hline & $\begin{array}{c}\alpha \\
(2)\end{array}$ & $\begin{array}{c}C_{r}=1 / \sqrt{\left(1+\beta_{c} \alpha\right)} \\
\text { (3) }\end{array}$ & & \\
\hline 50 & 0.710 & 0.458 & 0.464 & 0.99 \\
\hline 75 & 0.473 & 0.534 & 0.545 & 0.98 \\
\hline 100 & 0.355 & 0.589 & 0.603 & 0.98 \\
\hline 125 & 0.284 & 0.632 & 0.649 & 0.97 \\
\hline 150 & 0.237 & 0.666 & 0.685 & 0.97 \\
\hline 175 & 0.203 & 0.694 & 0.715 & 0.97 \\
\hline 200 & 0.177 & 0.718 & 0.740 & 0.97 \\
\hline & & & Average $=$ & 0.98 \\
\hline & & & dard deviation $=$ & 0.006 \\
\hline
\end{tabular}


Table 12 Effect of flexible twist end restraint on elastic critical moment for $2 \mathrm{~m}$ span Glulam cantilever with $80 \mathrm{~mm} \times 570 \mathrm{~mm}$ cross-section under UDL

\begin{tabular}{|c|c|c|c|c|}
\hline \multirow[b]{2}{*}{$\begin{array}{c}\text { Stiffness of twist end } \\
\text { restraint } \\
R(k N m / R a d) \\
\text { (1) }\end{array}$} & \multicolumn{2}{|c|}{ Present Solution } & \multirow[b]{2}{*}{$\begin{array}{l}\text { Finite element } \\
\qquad C_{r-F E A} \\
(4)\end{array}$} & \multirow[b]{2}{*}{$\begin{array}{c}\text { Ratio } C_{r} / C_{r-F E A} \\
\text { (5) }\end{array}$} \\
\hline & $\begin{array}{c}\alpha \\
(2)\end{array}$ & $\begin{array}{c}C_{r}=1 / \sqrt{\left(1+\beta_{c} \alpha\right)} \\
\text { (3) }\end{array}$ & & \\
\hline 50 & 0.710 & 0.306 & 0.405 & 1.05 \\
\hline 75 & 0.473 & 0.367 & 0.476 & 1.04 \\
\hline 100 & 0.355 & 0.414 & 0.530 & 1.03 \\
\hline 125 & 0.284 & 0.453 & 0.573 & 1.02 \\
\hline 150 & 0.237 & 0.487 & 0.608 & 1.02 \\
\hline 175 & 0.203 & 0.516 & 0.638 & 1.01 \\
\hline 200 & 0.177 & 0.541 & 0.663 & 1.01 \\
\hline & & & Average $=$ & 1.02 \\
\hline & & & dard deviation $=$ & 0.014 \\
\hline
\end{tabular}

\subsubsection{Load height coefficient}

A cantilever beam is subjected to a load $q(x)$ acting at a distance $y_{q}$ above the section centroid. The following displacement functions are postulated:

$$
\theta_{x}(x)=A\left[1-\cos \left(\frac{\pi x}{2 L}\right)\right], \quad u(x)=B\left[1-\cos \left(\frac{\pi x}{2 L}\right)\right]
$$

By substituting into Eq. (14), evoking the neutral stability condition, and setting to zero the resulting matrix of coefficients while adopting a non-uniform distributed load $q(x)$ instead of the uniform load $q$ and neglecting the last term in Eq. (14), one obtains $M_{c r}=\left[\bar{C}_{b}(\pi / L) \sqrt{E I_{y y} G J}\right]\left(\sqrt{1+\eta^{2}}-\eta\right), \quad$ where $\quad \eta=(k)\left(y_{q} / L\right) \sqrt{E I_{y y} / G J} \quad$ and $k=\varsigma \pi / 2 I_{4}, \quad \varsigma=L \int_{0}^{L}\left[q(x) / M_{0}\right][1-\cos (\pi x / 2 L)]^{2} d x$ which depend on the load distribution. For the case where all loads are applied at the section centroidal axis, one has $\eta=0$, and $M_{c r}$ reverts to the critical moment expression $M_{c r o}=\bar{C}_{b}(\pi / L) \sqrt{E I_{y y} G J}$ provided under section 8.2.2. By dividing $M_{c r}$ by $M_{c r 0}$, one recovers the sought load height coefficient $C_{L}$

$C_{L}=\left(M_{c r} / M_{c r 0}\right)=\left(\sqrt{1+\eta^{2}}-\eta\right)$ 
For the special case of a point load $P$ acting at the cantilever tip, one has $q(x)=P \times \operatorname{Dirac}(L), M(x)=-P L[1-(x / L)], M_{0}=-P L, k=1.27 \bar{C}_{b}$, and one recalls from section 8.2 .2 that $\bar{C}_{b}=4.63$. For the special case of a uniformly distributed load, one has $q(x)=q, M(x)=(q / 2)(L-x)^{2}, M_{0}=q L^{2} / 2$, and $k=1.15 \bar{C}_{b}$, and one recalls that $\bar{C}_{b}=9.41$. As discussed under Section 8.2.2, the moment gradient factors $\bar{C}_{b}=4.63$ and $\bar{C}_{b}=9.41$ computed from the above approximate procedure are grossly overestimated, and ought to be replaced by the moment gradients computed from FEA $C_{b}=C_{b-F E A}$ which take the values 1.28 and 2.05 (Section 8.2.1). An assessment of the validity of the above technique is provided through the following numerical example.

A cantilever with an $80 \mathrm{mmx} 570 \mathrm{~mm}$ cross-section and a span varying from $2-6 \mathrm{~m}$ is subjected to two top face loading scenarios; (1) Tip point load, and (2) UDL. The critical moment predictions based on the expression $M_{c r}=C_{b} C_{L} M_{u}$ with $C_{b}=C_{b-F E A}$ and $C_{L}$ is based on Eq. (30) are compared to those predicted by the FEA as obtained by dividing the critical moment of a cantilever subjected to top face loading by the critical moment subjected to centroid loading. Fig. 4 shows close agreement between the $C_{L}$ expression as given by Eq. (30) and that predicted by the FEA. For the tip load, the $C_{L} / C_{L-F E A}$ ratio varies from 0.96 to 1.00 with an average of 0.98 . For UDL, the ratio varies from 0.97 to 1.01 with an average value of 0.98 . 


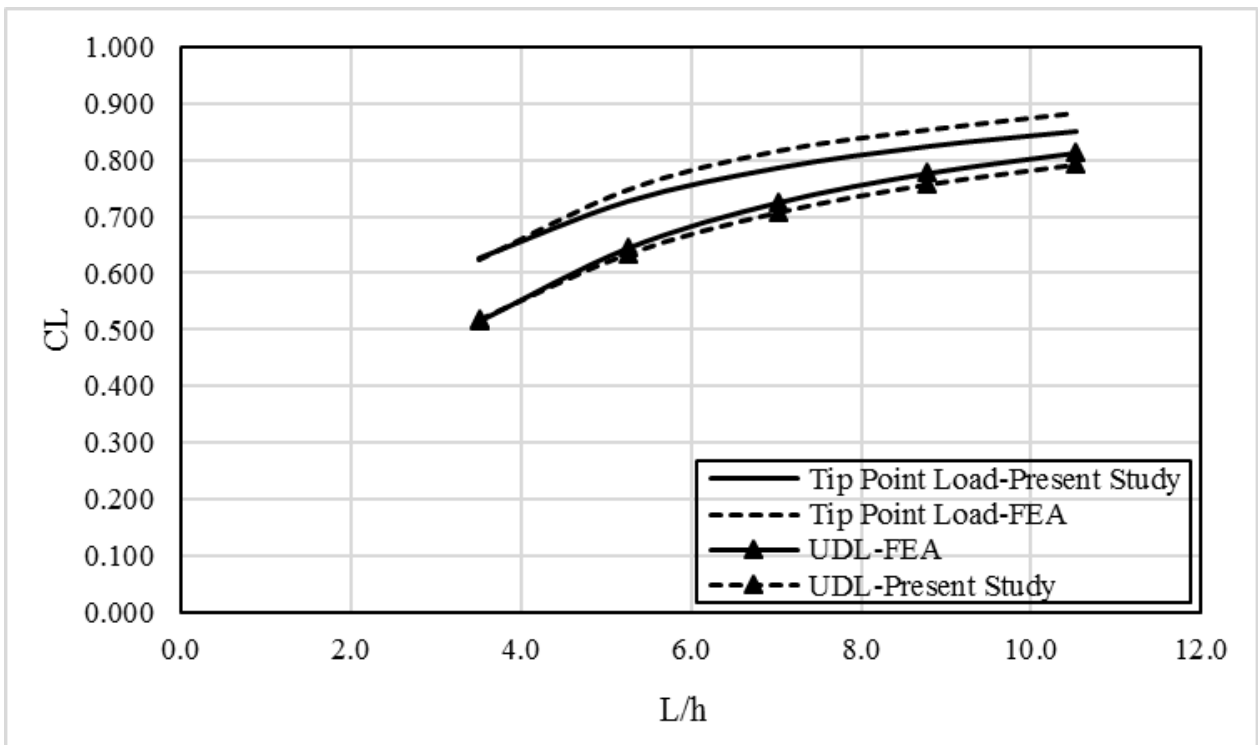

Fig. 4 Load height factor vs $\mathrm{L} / \mathrm{h}$ ratio

\subsubsection{Pre-buckling coefficient}

Consider a cantilever under a moment distribution $M(x)$ with a peak moment $M_{0}$. By assuming the buckling displacement fields to follow those postulated in Eq. (29)a-b, substituting into Eq. (23), and evoking the neutral stability condition, one obtains $M_{c r}=\bar{C}_{b} M_{u} / \sqrt{\left[1-\left(I_{y y} / I_{z z}\right)\right]\left[1+\left(\delta_{c} I_{y y} / I_{z z}\right)\right]}, \quad$ where one recalls that $M_{u}=(\pi / L) \sqrt{E I_{y y} G J}, \quad \delta_{c}=-1+8 \mu \bar{C}_{b}^{2}, \quad$ and $\mu=(1 / L) \int_{0}^{L}\left[M(x) / M_{0}\right]^{2}[1-\cos (\pi x / 2 L)]^{2} d x$. For the special case where one neglects the pre-buckling deformation effects, the expression for $M_{c r}$ reverts to the critical moment expression $M_{c r o}=\bar{C}_{b}(\pi / L) \sqrt{E I_{y y} G J}$. By dividing $M_{c r}$ by $M_{c r 0}$, one obtains the sought pre-buckling coefficient

$$
C_{p}=\left(M_{c r} / M_{c r 0}\right)=1 / \sqrt{\left[1-\left(I_{y y} / I_{z z}\right)\right]\left[1+\left(\delta_{c} I_{y y} / I_{z z}\right)\right]}
$$

Again, as discussed under Section 8.2.2, the moment gradient factors $\bar{C}_{b}$ computed from the above approximate procedure are grossly overestimated, and ought to be replaced by the moment gradients computed from FEA $C_{b}=C_{b-F E A}$ (Section 8.2.1). Hence, using 
$C_{b}=C_{b-F E A}$, for the special case of tip point load, $\delta_{c}$ in Eq. (31) takes the value $\delta_{c}=0.0840$ while for the case of uniformly distributed load one has $\delta_{c}=0.0253$.

Consider a cantilever with span $L=2 m$, a $570 \mathrm{~mm}$ deep cross-section, while the section width $b$ is assumed to vary from $80 \mathrm{~mm}$ to $210 \mathrm{~mm}$. Two loading cases are considered (1) tip point load and (2) uniformly distributed loading, both acting at the section centroid. The pre-buckling coefficient as determined by the proposed technique: $C_{p}=\left(M_{c r} / M_{c r 0}\right)=1 / \sqrt{\left[1-\left(I_{y y} / I_{z z}\right)\right]\left[1+\left(\delta_{c} I_{y y} / I_{z z}\right)\right]}, \delta_{c}=-1+8 \mu C_{b}^{2}$ are compared to those predicted by the FEA as obtained by dividing the FEA critical moment (including pre-buckling effects) by the critical moment without pre-buckling effect $C_{p-F E A}=M_{F E A} / C_{b} M_{u}$. As observed in Columns 5 and 8 of Table 13, excellent agreement is obtained between both solutions as the $C_{p} / C_{p-F E A}$ ratio is found to range from 0.99 to 1.00 in all cases considered.

Table 13 Pre-buckling coefficients for a $2 \mathrm{~m}$ cantilever

\begin{tabular}{|c|c|c|c|c|c|c|c|}
\hline \multicolumn{2}{|c|}{ Cross-sections } & \multicolumn{3}{|c|}{ Tip point load } & \multicolumn{3}{c|}{ Uniformly distributed load } \\
\hline $\begin{array}{c}b(\mathrm{~mm}) \\
(1)\end{array}$ & $\begin{array}{c}d(\mathrm{~mm}) \\
(2)\end{array}$ & $\begin{array}{c}C_{p} \\
\text { (Present Study) } \\
(3)\end{array}$ & $\begin{array}{c}C_{p-F E A} \\
(4)\end{array}$ & $\begin{array}{c}C_{p} \\
(5)=(3) /(4)\end{array}$ & $\begin{array}{c}C_{p} \\
\text { Present } \\
\text { Study }) \\
(6)\end{array}$ & $\begin{array}{c}\text { FEA } \\
(7)\end{array}$ & $(8)=(6) /(7)$ \\
\hline 80 & 570 & 1.01 & 1.01 & 1.00 & 1.01 & 1.01 & 1.00 \\
\hline 90 & 570 & 1.01 & 1.01 & 1.00 & 1.01 & 1.01 & 1.00 \\
\hline 100 & 570 & 1.01 & 1.01 & 1.00 & 1.01 & 1.01 & 1.00 \\
\hline 110 & 570 & 1.02 & 1.02 & 1.00 & 1.02 & 1.02 & 1.00 \\
\hline 120 & 570 & 1.02 & 1.02 & 1.00 & 1.02 & 1.02 & 1.00 \\
\hline 130 & 570 & 1.02 & 1.02 & 1.00 & 1.03 & 1.03 & 1.00 \\
\hline 140 & 570 & 1.03 & 1.03 & 1.00 & 1.03 & 1.03 & 1.00 \\
\hline 150 & 570 & 1.03 & 1.03 & 1.00 & 1.03 & 1.03 & 1.00 \\
\hline 160 & 570 & 1.04 & 1.04 & 1.00 & 1.04 & 1.04 & 1.00 \\
\hline 170 & 570 & 1.04 & 1.04 & 1.00 & 1.05 & 1.04 & 1.00 \\
\hline 180 & 570 & 1.05 & 1.05 & 1.00 & 1.05 & 1.05 & 1.00 \\
\hline 190 & 570 & 1.05 & 1.06 & 0.99 & 1.06 & 1.06 & 1.00 \\
\hline 200 & 570 & 1.06 & 1.06 & 1.00 & 1.06 & 1.06 & 1.00 \\
\hline 210 & 570 & 1.06 & 1.07 & 0.99 & 1.07 & 1.07 & 1.00 \\
\hline
\end{tabular}




\section{Combined effects}

In Section 8, the validity of each of the individual coefficients derived were established through comparisons with finite element solution. It is next of interest to assess the validity of the multiplicative expression postulated in Eq. (5). Towards this goal, the elastic critical moments are investigated for eight cases (Table 14). The problems are selected to cover different boundary conditions (either Simply Supported (SS) or Cantilever (C) in Column 2), spans (Column 3), and cross-sectional geometries (Column 4). Loading configurations included tip point loads for cantilevers, mid-span Point Load (PL) or Uniformly Distributed Load (UDL) (Column 5) and loads were applied at the section mid-height/shear centre (SC), Top Face (TF), or Bottom Face (BF) - (Column 6). Also, different levels of partial twist restraints at the ends were considered. Five cases considered pre-buckling deformation (marked as $\mathrm{Y}$ in Column 8) effects while the remaining three cases excluded pre-buckling effects (marked as N). In all cases, material properties were taken as $E=12800 \mathrm{MPa}$ and $G=E / 16$. All simply supported spans were selected such that elastic lateral torsional buckling governs the capacity according to CAN-CSA O86-14 provisions, while cantilever spans were selected in the inelastic buckling range. In both cases, the elastic critical moments were determined based on two solutions. The first one (Column 7 in Table 15) is based on the expression $M_{c r} \approx C_{r} C_{b} C_{L} C_{p} M_{u}$ proposed in Eq. (5), where coefficients $C_{r}, C_{b}, C_{L}, C_{p}$ are respectively provided in Columns 2-5 of Table 15 , and $M_{u}=(\pi / L) \sqrt{E I_{y y} G J}$ is provided in Column 6, and the second solution (Column 8) is based on the present finite element $M_{c r}(F E A)$ and is provided for benchmarking. Close agreement between both solutions is attained in all cases as the $M_{c r} / M_{c r}(F E A)$ ratio is found to vary from 0.95 to 1.02 with a mean value of 0.98 (Column 9). For cantilevers, while inelastic LTB resistance is expected to govern the capacity (as opposed to elastic LTB), design standards such as EN 1995-1-1: 2004 [30] estimate the inelastic LTB strength from the elastic buckling stress (as calculated by dividing the elastic LTB moment $M_{c r}$ by the elastic section modulus $S_{x}$ ). In this respect, the present study quantifies the elastic LTB moment $M_{c r}$ and serves as a means to determine the required inelastic LTB strength. 
Table 14 Cases investigated

\begin{tabular}{|c|c|c|c|c|c|c|c|}
\hline $\begin{array}{c}\text { Case } \\
(1)\end{array}$ & $\begin{array}{c}\text { Boundary } \\
\text { Condition } \\
(2)\end{array}$ & $\begin{array}{c}\text { Span } \\
(m) \\
(3)\end{array}$ & $\begin{array}{c}\text { Section } \\
\text { Designation } \\
b \times h \\
(m m \times m m) \\
(4)\end{array}$ & $\begin{array}{c}\text { Load } \\
\text { Type } \\
(5)\end{array}$ & $\begin{array}{c}\text { Load } \\
\text { Position } \\
(6)\end{array}$ & $\begin{array}{c}\text { Partial Twist } \\
\text { End Restraint } \\
(k N m / r a d) \\
(7)\end{array}$ & $\begin{array}{c}\text { Incorporate } \\
\text { Pre-buckling } \\
\text { Deformation } \\
\text { Effect? } \\
(8)\end{array}$ \\
\hline 1 & SS & 5 & $80 \times 380$ & PL & SC & $50 / 50$ & Y \\
\hline 2 & SS & 5 & $80 \times 380$ & UDL & BF & $50 / 100$ & N \\
\hline 3 & SS & 6 & $80 \times 570$ & PL & TF & $\infty / \infty$ & Y \\
\hline 4 & SS & 10 & $80 \times 570$ & UDL & BF & $1000 / 50$ & Y \\
\hline 5 & SS & 8 & $130 \times 646$ & PL & SC & $\infty / \infty$ & Y \\
\hline 6 & SS & 8 & $130 \times 646$ & UDL & TF & $500 / 500$ & Y \\
\hline 7 & $\mathrm{C}$ & 4 & $130 \times 646$ & PL & SC & $200 / 0$ & $\mathrm{~N}$ \\
\hline 8 & $\mathrm{C}$ & 4 & $130 \times 646$ & UDL & TF & $1000 / 0$ & \\
\hline
\end{tabular}

Table 15 Elastic critical moments

\begin{tabular}{|c|c|c|c|c|c|c|c|c|}
\hline \multirow{4}{*}{$\begin{array}{c}\text { Case } \\
(1)\end{array}$} & \multicolumn{9}{|c|}{ Present Study (Energy Solution) } & FEA & Ratio \\
\cline { 2 - 9 } & $\begin{array}{c}C_{r} \\
(2)\end{array}$ & $\begin{array}{c}C_{b} \\
(3)\end{array}$ & $\begin{array}{c}C_{L} \\
(4)\end{array}$ & $\begin{array}{c}C_{p} \\
(5)\end{array}$ & $\begin{array}{c}M_{u}(\mathrm{kNm}) \\
(6)\end{array}$ & $\begin{array}{c}M_{c r}(\mathrm{kNm}) \\
(2) \times(3) \times(4) \times(5) \times(6) \\
=(7)\end{array}$ & $\begin{array}{c}M_{c r}(\mathrm{kNm}) \\
(8)\end{array}$ & $(7) /(8)=(9)$ \\
\hline 1 & 0.793 & 1.36 & - & 1.02 & 60.72 & 66.8 & 68.1 & 0.98 \\
\hline 2 & 0.828 & 1.15 & 1.13 & - & 60.72 & 65.3 & 67.9 & 0.96 \\
\hline 3 & - & 1.36 & 0.84 & 1.01 & 77.81 & 89.4 & 87.4 & 1.02 \\
\hline 4 & 0.884 & 1.15 & 1.09 & - & 46.69 & 51.7 & 53.6 & 0.97 \\
\hline 5 & - & 1.36 & - & 1.02 & 277.8 & 385 & 385 & 1.00 \\
\hline 6 & 0.881 & 1.15 & 0.88 & 1.02 & 277.8 & 253 & 248 & 1.02 \\
\hline 7 & 0.560 & 1.28 & - & 1.02 & 555.5 & 406 & 416 & 0.98 \\
\hline 8 & 0.790 & 2.05 & 0.67 & - & 555.5 & 605 & 639 & 0.95 \\
\hline
\end{tabular}

\section{Summary and conclusions}

The present study contributed to the following:

1. A total potential energy functional has been specifically tailored for the lateral torsional buckling of wood beams with rectangular sections. The formulation omits warping effects, since they are negligible for rectangular cross-sections, but accounts for pre-buckling deformation effects and partial twist restraints. The functional was then used to develop a beam finite element formulation.

2. The predictions of the present finite element are consistently within $2 \%$ of to those based on 3D FEA results. This proximity is an indication of the validity of the present finite element and the underlying variational principle. The predictions of the present 
finite element (and 3D FEA models) are also in reasonable agreement with experimental results considering that the FEA does not account for the spatial variability of the mechanical properties nor the geometric imperfections in the tested specimens.

3. The validated variational expression was then used to develop approximate and relatively simple analytical expressions that characterize the effects of moment gradient, partial twist end restraints, load height, and pre-buckling deformation for common boundary conditions and loading cases.

4. The multiplicative rule proposed provides a basis to develop a generalized, transparent, and accurate framework to quantify the elastic lateral torsional buckling strength in wooden beams.

For a complete design framework, further developments are recommended to develop additional coefficients that incorporate out-of-straightness effects and resistance coefficients to incorporate the effect of material variability.

\section{Acknowledgements}

The third author gratefully acknowledges funding from the Natural Sciences and Engineering Research Council of Canada (NSERC) and additional in-kind contributions from the Canadian Wood Council (CWC). 


\section{References}

[1] CAN-CSA O86-14. Engineering design in wood. CSA-O86-14 2ed. CA: CSA Group; 2017.

[2] AFPA-TR14. Designing for lateral-torsional stability in wood members. AFPATechnical Report 14. Washington, DC, USA: American Forest \& Paper Association, Inc., American Wood Council; 2003.

[3] ANSI/AWC-NDS-2015. National design specification for wood construction. ANSI/AWC-NDS-2015. Leesburg, VA, USA: American Wood Council; 2015.

[4] Hooley RF, Madsen B. Lateral Stability of Glued Laminated Beams. Journal of the Structural Division. 1964;90:201-18.

[5] Hindman DP, Manbeck HB, Janowiak JJ. Measurement and prediction of lateral torsional buckling loads of composite wood materials : Rectangular sections. Madison, WI, ETATS-UNIS: Forest Products Society; 2005b.

[6] Hindman DP, Manbeck HB, Janowiak JJ. Measurement and prediction of lateral torsional buckling loads of composite wood materials: I joist sections. 2005a;v. 55.

[7] Balaz IJ. Lateral torsional buckling of timber beams. Wood Research. 2005;50:51-8.

[8] Burow JR, Manbeck HB, Janowiak JJ. Lateral Stability Considerations for Composite Wood I-Joists. 2005.

[9] Burow JR, Manbeck HB, Janowiak JJ. Lateral Stability of Composite Wood I-Joists Under Concentrated-Load Bending. 2006;v. 49.

[10] Xiao Q, Doudak G, Mohareb M. Numerical and experimental investigation of lateral torsional buckling of wood beams. Engineering Structures. 2017;151:85-92.

[11] Xiao Q, Doudak G, Mohareb M. LATERAL TORSIONBAL BUCKLING OF WOOD BEAMS: FEA-MODELING AND SENSITIVITY ANALYSIS. World Conference on Timber Engineering. Quebec City, Canada2014.

[12] Ivan Balaz, Kolekova Y. LATERAL TORSIONAL STABILITY OF TIMBER BEAMS. 6th International Conference on Mechanics and Materials in Design. Ponta Delgada, Portugal2015.

[13] Du Y, Mohareb M, Doudak G. Nonsway Model for Lateral Torsional Buckling of Wooden Beams under Wind Uplift. Journal of Engineering Mechanics. 2016b;142:04016104.

[14] Du Y. Lateral torsional buckling of wooden beam-deck systems. Ottawa: University of Ottawa; 2016.

[15] Du Y, Mohareb M, Doudak G. LATERAL TORSIONAL BUCKLING OF TWINBEAM-DECK ASSEMBLIES UNDER WIND UPLIFT - SWAY VERSUS NONSWAY MODELS. World Conference on Timber Engineering. Vienna, Austria2016a.

[16] Hu Y, Mohareb M, Doudak G. Effect of Eccentric Lateral Bracing Stiffness on Lateral Torsional Buckling Resistance of Wooden Beams. International Journal of Structural Stability and Dynamics. 2017a:1850027.

[17] Hu Y, Mohareb M, Doudak G. Lateral Torsional Buckling of Wooden Beams with Midspan Lateral Bracing Offset from Section Midheight. Journal of Engineering Mechanics. 2017b; 143:04017134.

[18] Buchanan AH. Combined Bending and Axial Loading in Lumber. Journal of Structural Engineering. 1986;112:2592-609. 
[19] Zahn JJ. Design of Wood Members Under Combined Load. Journal of Structural Engineering. 1986;112:2109-26.

[20] Zahn JJ. Combined-Load Stability Criterion for Wood Beam-columns. Journal of Structural Engineering. 1988;114:2612-28.

[21] Koka EN. Laterally loaded wood compression members: Finite element and reliability analysis. Vancouver: University of British Colombia; 1987.

[22] Bell K, Eggen TE. Stability of timber beams and columns. International Association for Bridge and Structural Engineering. Zurich, Switzerland: iabse symposium report; 2001. p. 30-6.

[23] Steiger R, Fontana M. Bending moment and axial force interacting on solid timber beams. Materials and Structures. 2005;38:507-13.

[24] Song X, Lam F. Three dimensional stability analysis of wood beam-columns. Proceeding 9th World Conference on Timer Engineering (WCTE). Cookeville, TN2006. p. 1061-7.

[25] Song X, Lam F. Laterally braced wood beam-columns subjected to biaxial eccentric loading. Computers \& Structures. 2009;87:1058-66.

[26] Song X, Lam F. Stability Capacity and Lateral Bracing Requirements of Wood Beam-Columns. Journal of Structural Engineering. 2010;136:211-8.

[27] Zahn J. Lateral stability of deep beams with shear-beam support. Madison, WI: Forest Products Laboratory; 1965.

[28] Zahn J. Shear stiffness of two-inch wood decks for roof systems. Madison, WI: Forest Products Laboratory; 1973.

[29] Zahn JJ. Bracing Requirements for Lateral Stability. Journal of Structural Engineering. 1984;110:1786-802.

[30] 1995-1-1:2004 E. Eurocode 5: Design of Timber Structures-General - Common rules and rules for buildings. Brussels, Belgium.: European Committee of Standardization (CEN); 2004.

[31] Krajcinovic D. A consistent discrete elements technique for thinwalled assemblages. Int J of Solids and Struct. 1969;5:639-62.

[32] Barsoum RS, Gallagher RH. Finite element analysis of torsional and torsionalflexural stability problems. International Journal for Numerical Methods in Engineering. 1970;2:335-52.

[33] Powell G, Klingner R. Elastic Lateral Buckling of Steel Beams. J of the Struct Div. 1970;96:1919-32.

[34] Erkmen RE, Mohareb M. Buckling analysis of thin-walled open members-A finite element formulation. Thin Wall Struct. 2008b;46:618-36.

[35] Attard MM, Kim M-Y. Lateral buckling of beams with shear deformations - A hyperelastic formulation. Int J of Solids and Struct. 2010;47:2825-40.

[36] Wu L, Mohareb M. Buckling formulation for shear deformable thin-walled members-II. Finite element formulation. Thin Wall Struct. 2011b;49:208-22.

[37] Erkmen RE. Shear deformable hybrid finite-element formulation for buckling analysis of thin-walled members. Finite Elements in Analysis and Design. 2014;82:3245.

[38] Sahraei A, Mohareb M. Upper and lower bound solutions for lateral-torsional buckling of doubly symmetric members. Thin Wall Struct. 2016;102:180-96. 
[39] Roberts TM, Burt CA. Instability of monosymmetric I-beams and cantilevers. International Journal of Mechanical Sciences. 1985;27:313-24.

[40] Pi Y, Trahair N. Prebuckling Deflections and Lateral Buckling. II: Applications. Journal of Structural Engineering. 1992b;118:2967-85.

[41] Andrade A, Camotim D. Lateral-torsional buckling of prismatic and tapered thinwalled open Pre-buckling deflection effects on stability of thin-walled beams with open sections beams: assessing the influence of pre-buckling deflections. Journal of steel and composite structures. 2004;4:281-301.

[42] Machado SP, Cortínez VH. Lateral buckling of thin-walled composite bisymmetric beams with prebuckling and shear deformation. Engineering Structures. 2005;27:118596.

[43] Erkmen RE, Attard MM. Lateral-torsional buckling analysis of thin-walled beams including shear and pre-buckling deformation effects. International Journal of Mechanical Sciences. 2011;53:918-25.

[44] Mohri F, Damil N, Potier-Ferry M. Pre-buckling deflection effects on stability of thin-walled beams with open sections. Steel and Composite Structures. 2012;13:71-89.

[45] Pezeshky P. Distortional static and buckling analysis of wide flange steel beams. Ottawa, ON, CA.: University of Ottawa; 2017.

[46] Pi Y, Trahair N. Prebuckling Deflections and Lateral Buckling. I: Theory. Journal of Structural Engineering. 1992a;118:2949-66.

[47] Xiao Q, Doudak G, Mohareb M. Numerical and Experimental Investigation of Lateral Torsional Buckling of Wood Beams. Engineering Structures. 2017; Accepted.

[48] Hu Y, Mohareb M, Doudak G. Lateral Torsional Buckling of Wooden Beams with Mid-span Lateral Bracing Offset from Section Mid-height. Journal of Engineering Mechanics. 2017:Accepted.

[49] Ádány S, Schafer BW. A full modal decomposition of thin-walled, single-branched open cross-section members via the constrained finite strip method. Journal of Constructional Steel Research. 2008;64:12-29.

[50] CAN-CSA S16-14. Handbook of Steel Construction. CSA-S16-14 Specification. 10th ed. CA: Canadian Institute of Steel Construction; 2014.

[51] ANSI/AISC 360-16. ANSI/AISC 360-16. Specification for structural steel buildings. Chicago, IL: American Institute of Steel Construction (AISC); 2016.

[52] AS-4100. AS 4100 steel structures. Sydney, Australia1998.

[53] Sahraei A, Pezeshky P, Mohareb M. Lateral torsional buckling analysis and design of steel beams with continuous spans. 6th International Conference on Engineering Mechanics and Materials. Vancouver, Canada2017a. p. EMM-635.

[54] Gardner L, Nerthercot DA. Designers' Guide to Eurocode 3: Design of Steel Buildings. 2nd ed: ICE, SCI; 2011. 